\title{
FATORES QUE AFETAM A DETERMINAÇĀO DO "VALOR L" E SUA COMPARAÇÃO COM A CAPACIDADE DE ADSORÇÃO DE FÓSFORO E O "VALOR E" EM DOIS SOLOS DO ESTADO DE SÃO PAULO
}

\author{
QUIRINO AUGUSTO DE CAMARGO CARMELLO \\ Engenheiro-agrônomo \\ Instituto Agronômico do Estado do São Paulo
}

Orientador: Dr. André Martin Louis Neptune

\begin{abstract}
Disserfação apresentada à Escola Superior de Agricultura "Luiz de Queiroz", da Universidade de São Paulo, para obłenção do título de Mestre em Energia Nuclear na Agricultura.
\end{abstract}

\footnotetext{
PIRACICABA

Estado de São Paulo - Brasil

Outubro, 1980
} 
ii.

A meus pais e irmãos

ofereço

A Lourdes e Bruno

dedico 


\section{AGRADECIMENTOS}

Agradeço às seguintes pessoas e instituições:

Prof. Dr. André Martin Louis Neptune pela orientação.

Dr. Bernardo van Raij e M.S. Takashi Muraoka pelo incentivo.

Centro de Energia Nuclear na Agricultura pela oportunidade con cedida e facilidades oferecidas.

PLANFAP/CNEN pela bolsa concedida durante os cursos.

CNPq pela bolsa de aperfeiçoamento, concedida durante a fase de redação.

Todos que de uma forma ou outra contribuíram neste trabalho. 


\section{IND I CE}

Pāg.

LISTA DE TABELAS .......................... vi

LITA DE FIGURAS $\ldots \ldots \ldots \ldots \ldots \ldots \ldots \ldots \ldots \ldots \ldots \ldots \ldots \ldots \ldots \ldots \ldots \ldots \ldots$

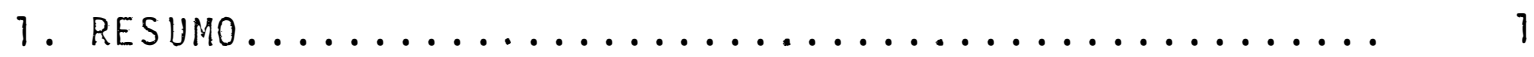

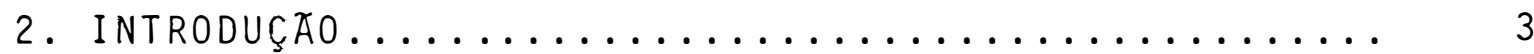

3. REVISAOO DE LITERATURA..................... 5

3.1. Princĩpio da diluição isotópica............ 5

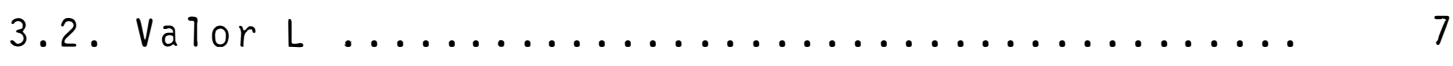

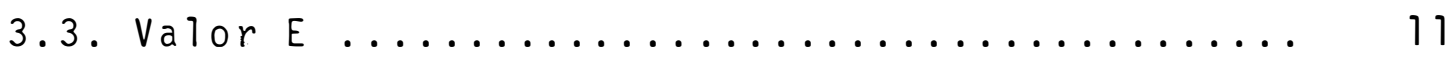

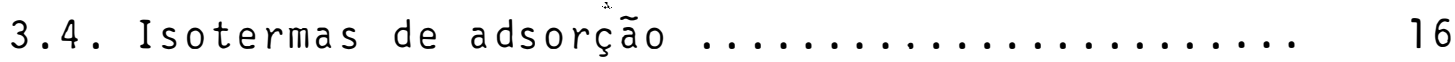

4. MATERIAIS E METODOS ....................... 20

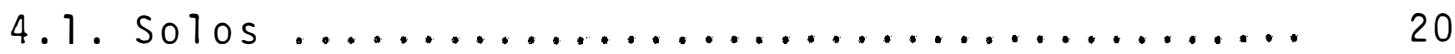

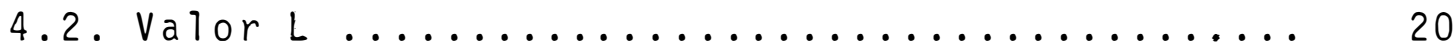

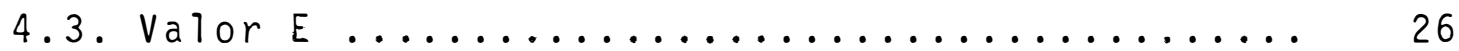

4.3.1. Influéncia da concentração da solução contendo 31p e $32 p \ldots \ldots \ldots \ldots \ldots . \ldots \ldots$

4.4. I sotermas de adsorção ............... 28 4.4.1. Influéncia do tempo de contato solo-so1 ução ...................... 28

4.4.2. Influéncia da concentração inicial da solução ...................... 29

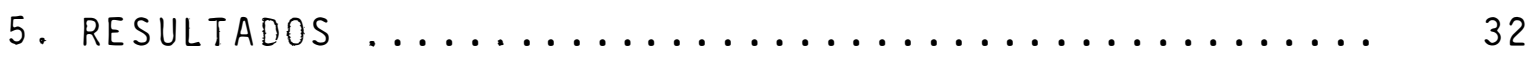

5.1. Ensaios para a determinação do Valor L ...... 32 5.1.1. Produção de material vegetal seco

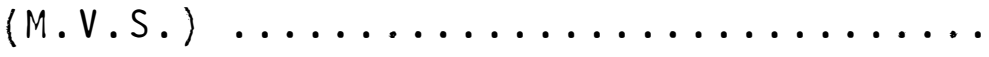


5.1.2. Absorção de fósforo pela planta ......

5.1.3. Atividade específica na planta .......

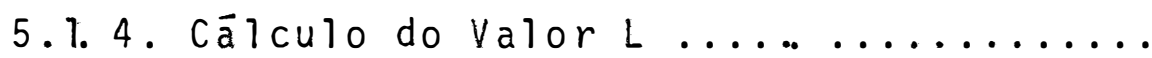

5.2. Ensaio para a determinação do valor E .......

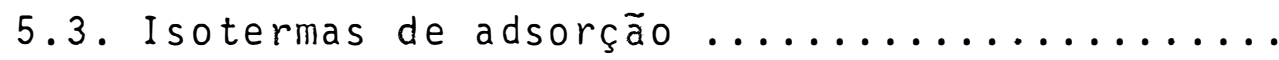

5.3.1. Influência do tempo de contato solo-so

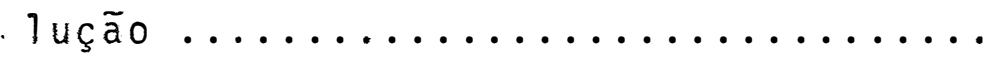

5.3.2. Influência da concentração inicial da

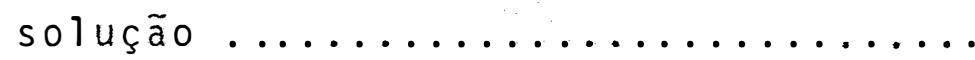

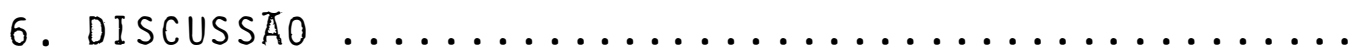

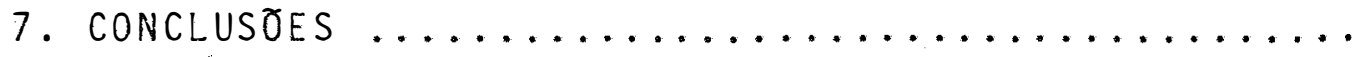

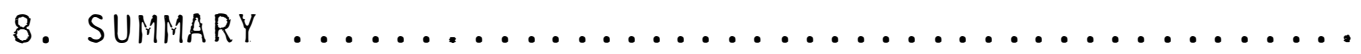

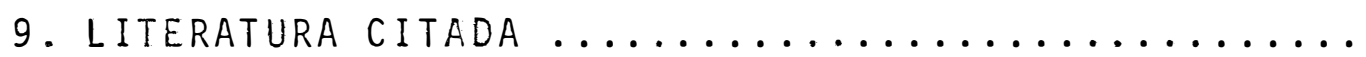




\section{LISTA DE TABELAS}

Pàg.

TABELA 1 - Características físicas, mineralōgicas e químicas dos solos estudados ...........

TABELA 2 - Quantidade de material vegetal seco (M.V.S.), produzidos por quilograma de so lo utilizado, expressas em gramas, para os quatro ensaios (mēdia de quatro repe-

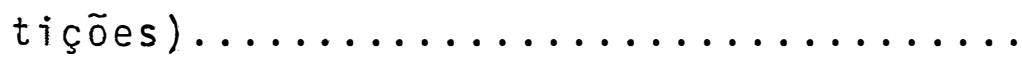

TABELA 3 - Quantidade de fósforo absorvidas por gra ma de M.V.S., expressas emmiligramas, pá ra os quatro ensaios (média de quatro re

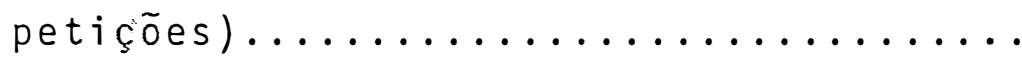

TABELA 4 - Atividades específicas, expressas em impulsos por miligrama de fósforo na planta, transformadas para $\sqrt{x+1}$, para os quatro ensaios (média de quatro repeti-

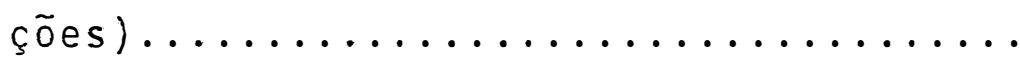

TABELA 5 - Valores L, expressos em miligramas de fós foro por quilograma de solo, para os quatro ensaios (média de quatro repetições)

TABELA 6 - Concentração de fósforo e atividade espe cífica da solução, antes e depois de 16 horas de contato solo-solução e o valor E calculado, para os dois solos (média de

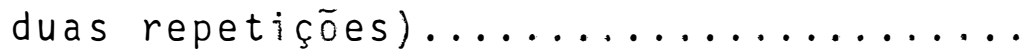


vii.

Pàg.

TABELA 7 - Concentração de fósforo na solução, expressa em $\mu \mathrm{g} / \mathrm{ml}$, com vārios tempos de con tato do sistema solo-solução, nos dois

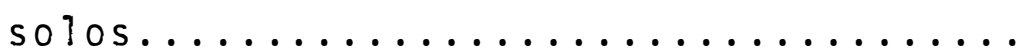

TABELA 8 - Concentração de fósforo na solução, expressa em $\mu \mathrm{g} / \mathrm{ml}$, apōs 16 horas de contato solo-solução, para diversas concentra ções iniciais, nos dois solos........... 


\section{- LISTA DE FIGURAS}

Pàg.

FIGURA 1 - Esquema de aplicação da solução contendo $31 p$ e $32 p$ ao solo dos vasos: A - em cama das; B - mistura com o solo e C - na su-

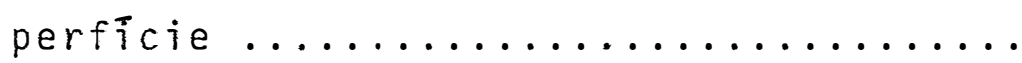

FIGURA 2 - Esquema de extração a vácuo, da solução que foi agitada com o solo ............

FIGURA 3 - Adsorção do fósforo presente na solução em função do tempo de agitação, para várias concentrações iniciais, dos dois so-

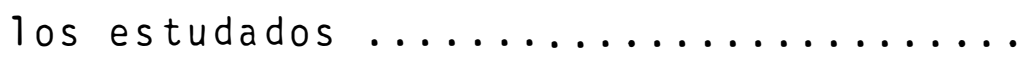

FIGURA 4 - Isoterma de adsorção de fósforo, pela equação de Freundlich, para os dois solos

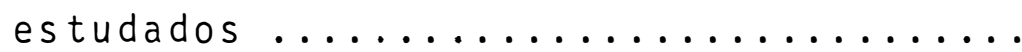

FIGURA 5 - Isoterma de adsorção de fósforo, pela equação de Langmuir, para os dois solos es

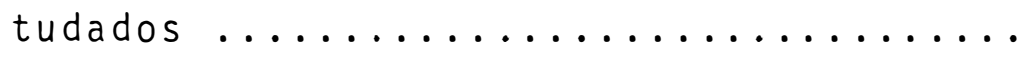




\section{RESUMO}

Em uma Terra Roxa Estruturada (TE) e um Podzólico Vermelho Amarelo - variação Piracicaba (PVP), estudou-se alguns fatores que poderiam afetar os resultados da determina ção do Valor L, comparando-se estes resultados com os do Valor $\mathrm{E}$ e das isotermas de adsorção determinados para os dois so los.

Os seguintes fatores foram considerados: 1) es pécies de planta (feijoeiro - Phaseolus vulgaris L. e milho Zea mays L.); 2) doses de fósforo ( 5 e $25 \mathrm{mg} / \mathrm{kg}$ de solo), com a mesma atividade específica; 3 ) quantidades de solo (1 kg, $3 \mathrm{~kg}$ e $5 \mathrm{~kg}$ ); 4) modos de aplicação (em camadas, mistura homogênea com o solo, na superfície e na superfície sem drenagem). Com base nos resultados deste trabalho, podemos concluir que: 1) os Valores L obtidos com os modos de aplicação, em camadas e mistura homogênea com o solo, com a do 
se de fósforo menor e com a quantidade de solo maior, são os que mais se aproximam dos valores obtidos com extratores quimicos; 2) os Valores L obtidos com as duas espécies e os dois solos são diferentes; 3 ) os Valores E e L obtidos são diferen tes; 4) à maior capacidade de adsorção do solo TE, correspondem os Valores E e L maiores, verificando-se o contrārio para o solo PVp; 5) a drenagem não afetou o Valor L. 


\section{INTRODUCÃO}

Entre os macronutrientes, o fósforo é um dos $\underline{e}$ xigidos em menores quantidades pelas plantas, embora, em solos tropicais seja o nutriente que mais limita a produção.

LARSEN (1974) calculou, com base no conteúdo de fósforo total, que a camada arável possui uma reserva da ordem de $2.000 \mathrm{~kg} P / \mathrm{ha}$. Se a remoção anual pelas culturas ē da ordem de 10 a $20 \mathrm{~kg} P /$ ha e, se as plantas removem de 10 a $30 \%$ do fósforo adicionado, então, existe uma fração do fósforo to tal que é lábil, isto é, potencialmente capaz de entrar na so lução do solo, durante o período de crescimento da planta(SUT TON e LARSEN, 1969) e outra fração que è não lábil, estando estas duas frações em equilíbrio iōnico dināmico.

Para se estudar a quantidade de fósforo do so10, que está na forma aproveitável pelas plantas, durante seu ciclo, inúmeros métodos foram propostos para estudos em labo- 
ratōrio e casa-de-vegetação. Assim, podemos citar: 1) métodos baseados na anālise do solo - a) extração química utilizando: soluções diluídas de ácido forte (TRUOG, 1930; NELSON et alii, 1953 e CATANI, 1947); soluções alcalinas (OLSEN, 1953): soluçoes diluĩdas de ācidos orgānico (FRIED e BROESHART, 1967); 吕 gua (BINGHAM, 1962 e PAAUW, 1971) e resina trocadora deānions (COOKE e HISLOP, 1962); b) utilizando o princĩpio da diluição isotōpica: Valor E (MCAULIFFE et alii, 1948 e RUSSELL etalii, 1954 ); 2) métodos utilizando microrganismos (VANDECAVEYÉ, 1948); 3) métodos baseados na anālise de plantas (VANDECAVEYE, 1948) e 4) métodos utilizando plantas e o princípio da diluição iso tōpica: Valor L (LARSEN, 1952 e RUSSELL et azii, 1954).

Diversos autores tem empregado a técnica do Va Ior L, proposta por LARSEN, 1952 e modificada por RUSSELL et alii, 1954, não havendo entretanto uma metodologia padronizada para seu emprego.

Visando propor uma metodologia que possa ser $\underline{u}$ sada como padrão, procurou-se estudar alguns fatores que pode riam afetar os resultados da determinação do Valor L, tentando-se tambēm comparar esses resultados com os do Valor E edas isotermas de adsorção de FREUNDLICH e LANGMUIR. 


\section{REVISÃO DE LITERATURA}

\subsection{Princípio da diluigão ISOTÓPICA}

o princīpio da diluição isotōpica baseia-se na reação entre dois átomos ou moléculas de mesmo nūmero atōmico, porēm com diferentes números de massa, que se substituem mutuamente, conforme a reação seguinte:

$$
A *+A B \rightleftharpoons A+A * B
$$

Quando o equilíbrio dessa reação de troca à atingido, a atividade específica do ātomo $A$ e do composto $A B$ são iguais.

Este fato permitiu que fosse proposto um método analîtico chamado diluição isotópica, que consiste na adição de uma quantidade conhecida de um isótopo radioativo ou es 
tāvel de abundāncia natural muito pequena, a um sistema em equilíbrio, que contenha esse elemento com composição isotópica natural, cuja concentração se deseja conhecer. Atingido o equilíbrio isotópico, é possível calcular-se a concentração do elemento no sistema em equilíbrio.

HEVESY e PANETH (1913), citados por HEVESY (1948), abriram a aplicação de isótopos em ciēncias biológi cas e químicas, utilizando o tōrio B (2l2pb) para estudar as solubilidades de sulfatos e cromatos de chumbo.

HEVESY (1948) cita também, que seu trabalho de 1920, introduziu a anālise por diluição isotópica, baseada no fato de que no equilíbrio isotópico, a atividade específica é constante através do sistema em estudo.

HEVESY (1923) estudou a absorção e a migração de chumbo em plantas, utilizando um traçador isotópico para a companhar sua distríbuição.

PANETH E VORWECK (1922), citados por FRIED (1964), estudaram a superficie específica de cristais de chum bo, utilizando troca isotópica.

HEVESY e HOFER (1934) estudaram a eliminação de āgua pelo corpo humano, usando a diluição isotópica.

MCAULIFFE et alii (1948) propõem que a reativi dade superficial de compostos pode ser estudada utilizando-se um isótopo radioativo de um dos elementos do composto, promovendo-se uma cinética de troca isotópica e inicia sua utiliza 
ção no estudo de fósforo em solos.

\subsection{VALOR L}

Valor L é a quantidade de fósforo do solo, na superfície das partículas e na solução do solo, que étrocável com ions ortofosfato adicionados à solução, ou seja, suscetí vel de participar da alimentação da planta (NEPTUNE e MURAOKA, 1978) e considerada como o fósforo lábil (GUNNARSON e FREDRIKSSON, 1951; SCHOFIELD, 1955; RUSSELL et alii, 1956; TALIBUDEEN, 1957; LARSEN E SUTTON, 1963 e NEWBOULD, 1963).

o Valor L é vālido se o fósforo adicionado era solūvel em água; se o equilíbrio isotópico foi atingido; se a disponibilidade do fósforo marcado não se alterou durante o crescimento da planta, se o fósforo sorvido esteve em equilíbrio com a solução; se o nível de carregador utilizado estava na faixa adequada; se o teor de fósforo da semente foi relati vamente desprezível e somente para a espécie de planta indica dora utilizada (NEPTUNE e MURAOKA, 1978).

LARSEN (1950 e 1952) afirma que quando um fertilizante fosfatado hidrosolúvel é adicionado a um solo emque quantidades e tipos de plantas diferentes estão crescendo, a anālise da atividade específica da planta pode resultar em um valor constante, se ocorrer a diluição isotópica do material a dicionado e se a medida for feita depois que o equilíbrio foi 
atingido, isto é, depois que a relação entre o fósforo proveniente do solo e do fertilizante se tornar constante.

LARSEN (1952) propõe que pela determinação da proporção entre $0{ }^{32}$ p originalmente presente no fertilizante adicionado e o encontrado na planta, depois de 7 semanas ou mais, pode-se calcular pela equação 1 , a quantidade de fósforo trocável do solo, a qual é independente da quantidade adicionada.

$$
Y=\left(\frac{C_{0}}{C}-1\right) x
$$

onde:

$$
\begin{aligned}
& Y \text { - } \text { fração do fósforo do solo que toma parte na diluição } \\
& \text { isotópica, e portanto, chamada fósforo trocável, ex- } \\
& \text { pressa em mgP/kg de solo. } \\
& c_{0} \text { e C - radioatividade no fertilizante e na planta, respecti } \\
& \text { vamente, expressas em i/min. } \\
& X \text { - quantidade de fósforo adicionada, expressa em mgP/kg } \\
& \text { de solo. }
\end{aligned}
$$

GUNNARSON e FREDRIKSSON (1951) afirmam, baseados em um experimento em vasos, com duas doses de superfosfato - $32 p$, que um valor constante pode ser calculado a partir da relação entre o fósforo do solo e do fertilizante. 
RUSSELL et alii (1954) introduziram modificações na equação 1 e propuseram a denominação Valor $L$.

$$
L=\frac{Y_{f}\left(x_{p}-D\right)}{Y_{p}}-x_{f}
$$

onde:

$\gamma_{f}$ e $Y_{p}$ - atividade do fertilizante e da planta, expressas em i/min e i/min/vaso, respectivamente.

$x_{f}$ e $x_{p}$ - fósforo adicionado e o encontrado na planta, expres sos mgP/kg de solo e mgP/vaso, respectivamente.

D - conteūdo de fósforo da semente, expresso em mgP/vaso.

O fator $D$ foi introduzido, visto que LARSEN (1952) já observara que a porcentagem de fósforo na plantapro veniente do fertilizante crescia até 40 a 50 dias, ficando somente apōs esse período. LARSEN supós que esse fato fosse de vido à grande influência exercida pelo fósforo da semente nas primeiras semanas, e que ela diminuía à medida que a planta éx plorava um maior volume de terra.

NEPTUNE MENARD (1963) observou que mesmo após 55 dias, uma certa quantidade de fósforo continua na semente. Em 1964, trabalhando com sementes de arroz, obteve que somente $65 \%$ do fósforo da semente passava para a parte aérea da 
planta até o final do ciclo.

LAMM (1961) e VOLK e MCLEAN (1963) admitem a in fluência do fósforo da semente e supōem que de 20 a $50 \%$ dofós foro da semente migraria para a parte aērea da planta.

NEPTUNE E MURAOKA (1980) obtiveram que apōs 1 mês de idade, o fósforo da semente havia migrado para a parte aérea e raiz, em $65,6 \%$ e $13,7 \%$, respectivamente, para sementes de feijão e $59,5 \%$ e $10,4 \%$ para sementes de arroz.

NEPTUNE e CAMPANELLI (196i) verificaram que quanto mais rico em fósforo for o solo, menor é a influēncia da semente no resultado de Valor L. Então, para solos pobres, - fósforo da semente pode alterar a atividade especifica, prin cipalmente em experimentos de curta duração.

LARSEN e COOKE (1961) a firmamque a correção do fósforo da semente deve ser feita, somente se soubermos quanto do fōsforo na planta veio da semente e que para o azevém o cálculo do Valor $L$ deve ser feito somente no terceiro corte, pois nos dois primeiros, a semente ainda tem grande influên cia. LARSEN e SUTTON (1963) afirmam que com 10 semanas, no quarto corte, o equilíbrio jā havia sido atingido e não havia efeito da semente.

ANDERSEN et azi determinaram alguns fatores que influenciam os resultados da determinação do Valor L, observando que ele aumenta durante o crescimento da planta e que os maiores valores foram encontrados, quando se usou vasos me 
nores, sendo nesse caso, tambēm maiores as quantidades de fós foro absorvido pelas plantas. Resultados semelhantes foram e contrados por LARSEN E SUTTON (1963).

FRIED (1964) afirma que a interação entre o fós foro adicionado e a superfície das partículas do solodeveser maximizada pela longa duração do experimento e sugere que a planta deva crescer até a maturação, para que a troca isotópi ca seja máxima, mas os prazos entre o plantio e a colheita das plantas tem variado com os diversos autores, assim, ANDERSEN e MOGENSEN (1963) colheram o azevém com dois meses; SUTTON e LARSEN (1969) fizeram seis cortes de azevēm, atē o sexto mês e FARDEAU e JAPPE (1976) fizeram trēs cortes de azevém até o terceiro més.

\subsection{VALOR E}

Valor E é a quantidade de fósforo associada à fase sōlida, mas suscetivel de trocar-se, isto é, a quantidade de ion ortofosfato na superficie das partículas e na solução do solo, que é trocável com íons ortofosfato idēnticos qui micamente, adicionados à solução e determinado em láboratório (FRIED, 1964).

o Valor E é válido se o fósforo adicionado era solūvel em ägua; se o equỉíbrio isotópica foi atingido; se o fósforo sorvido esteve em equilíbrio com a solução; se o ní- 
vel de carregador utilizado estava na faixa adequada, isto é, sua relação com o Valor E determinado não é alta; se não houve interferéncia de outros ions presentes na solução e se não houveram erros de medida (NEPTUNE e MURAOKA, 1978). MCAULIFFE et a.lii (1948), aplicando o principio da diluição isotópica a solos, estudaram o fosfato de superfície - 3lp, utilizando, após o equilíbrio, a equação 3 .

$$
\text { Fosf.de superf. }-33 p=\text { Fosf. na sol } .-31 p . \frac{\text { Fosf. de superf. }-32 p}{\text { Fosf. na sol. }-32 p}
$$

WIKLANDER (1950), utilizou esse conceito para estudar o fósforo trocável adsorvido à superfície das partículas do solo, denominando-o $P_{e}$ e rearranjando a equação 3 , que tomou a forma da equação 4.

$$
P_{e}=\left(\frac{32 p \text { adicionado }}{32 p \text { na solução }}-1\right) 31 p \text { na solução }
$$

GUNNARSON e FREDRIKSSON (1951) estudaram o fos fato de superfície, referindo-se a ele, como a fração do fósforo do solo, que é disponível às plantas. Sugerem que pode ria ser possivel determinar-se essa quantidade defósforo, pe1 a extração, em laboratório, de uma certa quantidade de solo, com uma solução de fósforo lábil.

RUSSELL et alii (1954) chamam essa fração do 
fósforo do solo de fösforo isotopicamente trocāvel, e propõem - termo Valor $E$, e a equação adquire as seguintes formas:

$$
E_{t}=\left(\frac{X_{t}}{Y_{t}}\right) y-x
$$

Ou

$$
\begin{gathered}
\left.E_{t}=x \frac{S_{0}}{S_{e}}-1\right) \\
\text { Ou ainda, quando se utilizava } 32 p \text { livre de car }
\end{gathered}
$$

regador

$$
E_{t}=\frac{c}{S_{e}}
$$

onde:

$X$ e $Y$ - quantidades de ${ }^{31} p$ e ${ }^{32 p}$, respectivamente, presentes na solução inicial.

$X_{t}$ e $Y_{t}$ - quantidades de ${ }^{31} p$ e ${ }^{32} p$, respectivamente, determinados na solução apōs um tempo t.

$S_{0}$ e $S_{e}$ - atividades específicas do composto adicionado e na solução no tempo t, respectivamente. C - atividade adicionada ao sistema.

Vārios autores estudaram o fosfato de superfí- 
cie, ou fósforo isotopicamente trocável ou Valor E, entre eles, podemos citar: AMER et azii (1955), AMER (1962), ANTIPOVKARATAEV (1956), ARAMBARRI e TALIBUDEEN (1959), CHO (1961), DEAN e RUBINS (1945), FIFE (1962), FRIED (1957), MATTINGLY e TALIBUDEEN (1960), MCAULIFFE et alii (1948), OLSEN (1952), RENNIE e MCKERCHER (1959), RUSSELL et arii (1954), RUSSELL (1959), SEATZ (1954), SOKOLOV (1959), TALIBUDEEN (1954 e 1957) e ULRICH (1961).

A técnica do Valor E inclui a agitação do solo com a solução contendo $32 p$, para que o equilíbrio isotópico seja atingido mais rapidamente. Os tempos de agitação tem variado muito de um autor para outro, assim, AMER (1962) usou 30 minutos, RENNIE e MCKERCHER (1959) utilizaram 1 hora, MATTIN GLY e TALIBUDEEN (1960) variaram de 20 a 170 horas, RUSSELL et alii (1954) e FRIED (1957) usaram 48 horas, OLSEN (1952) variou de 50 a 70 horas, KAFKAFI e BAR-YOSEF (1969) agitaram 3 dias, GUNNARSON e FREDRIKSSOiv (1951) e SOKOLOV (1956) utiliza ram 14 dias e ANDERSEN e HOGENSEN (1963) agitavam 1 hora por dia, durante 4 semanas.

Outros fatores que podem afetar o resultado da determinação do Valor E são: presença de íons orgānicos (ARAM BARRI e TALIBUDEEN, 1959), quantidade de bases trocáveis (ARAMBARRI e TALIBUDEEN, 1959; RUSSELL et alii, 1954 e WIKLAN DER, 1950), temperatura (ARAMBARRI e TALIBUDEEN, 1959 e WIKLANDER, 1950), tempo de agitação antes da adição do $32 p$ (AMER, 1962), secamento do solo durante a determinação (RUSSELL 
et alii, 1954 e WIKLANDER, 1950), proporção solo-solução (McAULIFFE et arii, 1948 e TALIBUDEEN, 1957).

McCONAGHY et alii (1967) demonstraram que o Va Ior E é uma medida do fator quantidade ou seja, do fósforo dis ponível e que é resultante do quociente entre o fator intensi dade (IDF) ou concentração de fósforo na solução do solo e o fator capacidade $\left(C_{t} / C_{j}\right)$ ou capacidade tampão do fósforo do solo, como aparece na equação 8 , que pode ser comparada coma equação 7 .

$$
E=I D F \cdot \frac{C_{i}}{C_{t}}
$$

onde:

IDF - fator de diluição isotōpica ou concentração de 31 P na solução no tempo.

$c_{i}$ e $c_{t}$ - atividade da solução inicial e no tempo $t$, respecti vamente.

LARSEN E SUTTON (1963) afirmam que teoricamente, na determinação do fósforo 1 ábil do solo por métodos de dí 1 uição isotópica, o fósforo não pode ser retirado do sistema, até que seja atingido o equilíbrio isotópico e isso só pode ser obtido na determinação do Valor E, porque na determinação do Valor L, é inevitāvel a absorção de fósforo pela planta,an 
tes que ocorra o equilibrio.

FRIED (1964) afirma que o Valor E tem sido usa do para predizer se um determinado solo tem nutriente suficiente para alimentar uma planta e como para uma amostragemda solução do solo poder ser utilizada para esse fim, teoricamen te é necessārio que ela tenha o mesmo valor e grau de uma plan ta amostrando o sistema, inclusive o efeito que a planta exer ce sobre o sistema, e isso, só uma planta poderia fazer.

RUSSELL et alii (1957) consideram que os dois valores são suficientemente iguais para serem vistos como medidas alternativas, e que a escolha entre eles deve depender, principalmente da conveniência e da economia de trabalho e por tanto, o Valor E é preferível, mas ele necessita de um método de planta como termo de referéncia.

FARDEAU e JAPPE (1976) afirmam que, pela extra polação de cinéticas breves, de 30 segundos a 100 minutos, de diluição isotópica pode-se obter muito simplesmente os valores $L$ do segundo, terceiro e quarto cortes de azevēm, feitos nose gundo, terceiro e quarto meses, respectivamente, e pela econo mia de tempo acreditam ser a medida do Valor E preferível.

\subsection{Isotermas de AdSOR\&ÃO}

Com a finalidade de possibilitar o estudo de processos de adsorção, isto é, a concentração de um liqquido ou 
um gás sobre a superfície de um sōlido, a equação 9 foi pro posta. Embora seja bem conhecida como isoterma de Freundich ela de fato foi sugerida pela primeira vez por BEMMELEN (1888), citado por SPOSITO (1980).

$$
\frac{x}{M}=K^{\prime} C^{n}
$$

onde:

$$
\begin{aligned}
& \text { C - concentração de equilíbrio. } \\
& \text { X/M - quantidade de adsorvido por unidade de adsorvente. } \\
& K^{\prime} \text { e } n \text { - constantes para uma certa combinação adsorvente - ad- } \\
& \text { sorvido, mas sem qualquer significado físico }(0<n<1), \\
& \text { jā que a equação é empirica. }
\end{aligned}
$$

A equação 9 pode ser utilizada para estudar-se a adsorção de ions por sōlidos. Ela é vālida para uma variação pequena de concentrâção de equilíbrio (BARROW, 1961) e po de ser apresentada para a forma linear, através da transforma ção logarîtmica, como na equação 10 .

$$
\log \frac{X}{M}=\log K^{\prime}+n \log C
$$

$$
\text { OLSEN e WATANABE (1957) afirmam que a equação }
$$
10 é freqüentemente utilizada em estudos de adsorção de nutrientes pelas partículas de solos, mas que nãoépossível cal 
cular-se com ela a adsorção máxima.

Jā a isoterma de Langmuir proposta para o estü do da cinëtica de gases (LANGMUIR, 1918) e utilizada para adsorção de gases por superfícies sōlidas pode tambëm ser aplicada no estudo da adsorção de líquidos e ions por sōlidos. A equação 11 foi deduzida e representa essa isoterma.

$$
\frac{x}{m}=\frac{K b C}{1+K b}
$$

onde:

X/m - quantidade de adsorvido por $100 \mathrm{~g}$ de adsorvente.

C - concentração de equilî́brio expressa em moles/l.

b - adsorção māxima.

K - constante relacionada com a energia de ligação.

Essa equação tambēm pode ser expressa na forma linear e é apresentada como equação 12.

$$
\frac{c}{x / m}=\frac{1}{k b}+\frac{c}{b}
$$

A isoterma de Langmuir somente pode ser usada para soluções diluĩdas, mas apresenta a vantagem de possibił tar o cálculo da adsorção máxima, que está relacionada com propriedades do solo e pode esclarecer a natureza das reações so 
10-fertilizante fosfatado (OLSEN e WATANABE, 1957). GUNARY (1970) explica que a equação 11 foi deduzida a partir de uma única camada iōnica adsorvida à superfície de uma partícula, com energia de ligação constante e BARROW (1961) afirma que a forma da isoterma é característica da adsorção de uma monocamada de ions pela fase sólida adsorvente do solo.

UDO e UZU (1972) afirmam que os compostos de $\underline{a}$ luminio apresentam maior capacidade de adsorção que os de fer ro. BITTENCOURT e ZAMBELLO (1973) encontraram boas correlações entre adsorção máxima e os teores de argila e ōxidos de ferro livre. LOURENÇO (1973) encontrou boas correlações somen te entre adsorção máxima e os teores de carbono e entre a adsorção máxima e o Valor E com 250 ppm de carregador. 


\section{MATERIAIS E METTDDOS}

\subsection{SOLOS}

Para a execução deste trabalho, foram coleta das amostras compostas dos $20 \mathrm{~cm}$ superiores de duas unidades de solo, localizadas na Estação Experimental de Capão Bonito (Instituto Agronômico do Estado de São Paulo) e na Fazenda Areão (Escola Superior de Agricultura "Luiz de Queiroz") em Pi racicaba.

$$
\text { Os solos foram classificados como Podzólicover }
$$
melho-Amarelo-variação Piracicaba (PVp) segundo o Levantamento de Reconhecimento dos Solos do Estado de São Paulo (1960) e Terra Roxa Estruturada (TE) segundo SUHET (1976), respectivamente.

$$
\text { O solo PVp estava sendo usado como pastagem de }
$$

grama Batatais e o TE estava coberto com pasto natural. Os so 
los nunca receberam adubação antes e suas características físicas, mineralōgicas e químicas são apresentadas na Tabela 1.

TABELA 1 - Características físicas, mineralógicas e químicas dos solos estudados.

A) ANÁLISE FISICA

Solos Argila Silte Areia Fina Areia Grossa Classificação

\begin{tabular}{lllllc}
\hline PVp & 27,0 & 24,9 & 39,4 & 8,7 & Fino argiloso \\
TE & 34,1 & 36,8 & 20,7 & 8,4 & Fino arg. siltoso \\
\hline
\end{tabular}

B) ANÁLISE MINERALOGICA DA FRAÇAO ARGILA

\begin{tabular}{ll}
\hline Solos & Minerais Presentes \\
\hline PVP & Caolinita, Gibbsita e Quartzo \\
TE & Caolinita e Quartzo \\
\hline
\end{tabular}

C) ANÁLISE QUIMICA PARA AVALIAR A FERTILIDADE

\begin{tabular}{|c|c|c|c|c|c|c|c|}
\hline \multirow[t]{2}{*}{ Solos } & \multirow{2}{*}{$\begin{array}{c}\mathrm{pH} \\
\mathrm{H}_{2} \mathrm{O}\end{array}$} & \multirow{2}{*}{$\begin{array}{c}\text { M. } 0 . \\
(\%)\end{array}$} & $\mathrm{Al}^{3+}$ & $\mathrm{Ca}^{2+}$ & $\mathrm{Mg}^{2}+$ & $\mathrm{K}^{+}$ & $P$ \\
\hline & & & \multicolumn{3}{|c|}{$\mathrm{e} . \mathrm{mg} / 100 \mathrm{ml}$} & \multicolumn{2}{|c|}{$\mu \mathrm{g} / \mathrm{ml}$} \\
\hline$P V p$ & 5,0 & 3,2 & 0,5 & 1,6 & 0,5 & 38 & 8 \\
\hline TE & 6,4 & 4,7 & 0,0 & 6,2 & 1,7 & 289 & 2 \\
\hline
\end{tabular}

D) ANÁLISE QUIMICA DOS TEORES TOTAIS

\begin{tabular}{lrrrrr}
\hline \multirow{2}{*}{ Solos } & $\mathrm{P}_{2} \mathrm{O}_{5}$ & $\mathrm{SiO}_{2}$ & $\mathrm{Al}_{2} \mathrm{O}_{3}$ & $\mathrm{Fe}_{2} \mathrm{O}_{3}$ & $\mathrm{TiO}_{2}$ \\
\cline { 2 - 6 } & & \multicolumn{5}{c}{$(\%)$} \\
\hline PVP & 0,042 & 9,55 & 10,35 & 2,75 & 0,63 \\
TE & 0,093 & 11,54 & 13,08 & 18,70 & 6,19 \\
\hline
\end{tabular}


Para a anālise física, seguiu-se o mëtodo da pi peta, descrito por KILMER e ALEXANDER (1949). Na anālise mine ralōgica da fração argila, seguiu-se a metodologia descrita por JACKSON (1969), utilizando-se um difratómetro de raios-X e identificando-se os minerais por seus espaçamentos basais.

Para a análise química visando avaliar a ferti lidade dos solos, seguiu-se a metodologia descrita por RAIJ e ZULLO (1977) e na anālise dos teores totais de P, Si, Al, Fe e Ti, seguiu-se a metodologia descrita por VETTORI (1969).

\subsection{VALOR L}

Para este estudo, instalou-se em casa-de-vegetação, quatro ensaios com os dois solos já mencionados (PVp e TE), utilizando feijoeiro e milho como plantas indicadoras, re cebendo os ensaios as seguintes denominações: TE-feijoeiro, TE-milho, PVp-feijoeiro e PVp-milho.

Em cada ensaio estudou-se as influéncias dos se guinies fatores sobre o Valor L: 1) quantidade de solo utilizada (1 kg, $3 \mathrm{~kg}$ e $5 \mathrm{~kg}$ de solo); 2) quantidade de $31 \mathrm{p}$ adicio nado ao solo com o ${ }^{32 p}$ (5 mg e $25 \mathrm{mg}$ de $\mathrm{P} / \mathrm{kg}$ de solo); 3) 10cal de aplicação da solução ao solo (em camadas, mistura com todo o solo e na superfície) 4) existència ou não de drenagem.

Desta forma, cada ensaio tinha 24 tratamentos, 
sendo os 8 tratamentos básicos, para cada quantidade de solo, relacionados a seguir:

1 - 5 mg $31 \mathrm{p} / \mathrm{kg}$ de solo, aplicados em camadas, com drenagem 2 - $5 \mathrm{mg} 31 \mathrm{p} / \mathrm{kg}$ de solo, misturados com o solo, com drenagem 3 - $5 \mathrm{mg} 31 \mathrm{p} / \mathrm{kg}$ de solo, aplicados à superfície, com drenagem 4 - $5 \mathrm{mg} 31 \mathrm{p} / \mathrm{kg}$ de solo, aplicados à superfície, sem drenagem $5-25 \mathrm{mg} 31 \mathrm{p} / \mathrm{kg}$ de solo, aplicados em camadas, com drenagem $6-25 \mathrm{mg} 31 \mathrm{p} / \mathrm{kg}$ de solo, misturados com o solo, com drenagem $7-25 \mathrm{mg} 31 \mathrm{p} / \mathrm{kg}$ de solo, aplicados à superfície, com drenagem $8-25 \mathrm{mg} 31 \mathrm{p} / \mathrm{kg}$ de solo, aplicados à superfície, sem drenagem

Seguiu-se o delineamento experimental inteiramente casualizado, fazendo-se 4 repetições por tratamento.

Os solos dos vasos, antes de receberem a solução de fósforo, foram adubados com $N$ e K na forma de uréia e cloreto de potāssio, na base de $200 \mathrm{~kg} \mathrm{~N} / \mathrm{ha}$ e $750 \mathrm{~kg} \mathrm{~K} \mathrm{~K}_{2} \mathrm{O} / \mathrm{ha}$, de forma que para o feijoeiro, adicionou-se $296 \mathrm{mg}$ de uréia / $\mathrm{kg}$ de solo e $167 \mathrm{mg}$ de $\mathrm{KCl} / \mathrm{kg}$ de solo e para o milho, as quan tidades foram $592 \mathrm{mg}$ e $334 \mathrm{mg}$, respectivamente. Como a solução de fósforo foi preparada com fosfato monobāsico de potássio, descontou-se na adubação potássica, o potássio que acompanhava os $5 \mathrm{mg}$ e $25 \mathrm{mg} P$ adicionados por $\mathrm{kg}$ de solo, relativos a cada tratamento.

Nos tratamentos em que a aplicação foi feita em camadas, o solo era colocado nos vasos, de forma que a solu- 
ção contendo $31 p$ e $32 p$, dividida em 3 partes, foi colocado, em cada vaso, sobre 3 camadas de $300 \mathrm{~g} / \mathrm{kg}$ de solo, forma que a ū tima destas camadas foi recoberta com $700 \mathrm{~g} / \mathrm{kg}$ de solo (Figura $1 A)$.

Nos tratamentos em que se fez a mistura com to do o solo, a solução contendo $31 \mathrm{p}$ e $32 \mathrm{p}$ foi colocada em $250 \mathrm{~g}$, $500 \mathrm{~g}$ e $750 \mathrm{~g}$ de solo, para as quantidades $1 \mathrm{~kg}, 3 \mathrm{~kg}$ e $5 \mathrm{~kg}$, respectivamente. Depois de seca em estufa e destorroadas, estas quantidades de solo marcado, foram muito bem misturadas com seus respectivos solos restantes, sobre um plástico, pela união dos vértices do quadrado, sendo o solo então colocado nos vasos (Figura IB).

Nos demais tratamentos, a solução contendo $31 \mathrm{p}$ e $32 p$ foi colocada na superfície do solo, nos vasos (Figura 1C)

A solução contendo 31 p e $32 p$ tinha a concentra ção $1 \mathrm{mg} P / \mathrm{ml}$ e a atividade específica $1 \mu \mathrm{Ci} / \mathrm{mg}$ P. Desta forma, o volume de solução e a atividade aplicados a cada vaso, era igual ao produto da quantidade de 31 p do tratamento, pela quantidade de solo desse tratamento.

os vasos foram pintados internamente com neutrol, sendo que ao final de cada ensaio eles foram lavados e uma nova demão de neutrol aplicada, antes do início do ensaio seguinte. Para os tratamentos com drenagem, havia, na parte in ferior dos vasos, orifícios, dos quais saíam pedaços de tubo 
plástico, que os uniam ao interior de garrafas de um litro de capacidade, cor àmbar, de forma que os possiveis excessos de solução do solo eram drenados e acumulavam nas garrafas. Por ocasião da rega seguinte, o conteūdo das garrafas era recolocado à superfície dos solos, sendo o interior das garrafas la vado, e a lavagem também adicionada à superfície. Nos trata mentos sem drenagem, os orificios foram obstruídos e as regas seguiram a mesma ocasião e volume de àgua aplicados dos trata mentos com drenagem.

Na semeadura, 3 e 2 sementes de feijão e milho respectivamente, foram colocadas por quilograma de solo. Após - desbaste, para cada quilograma de solo, deixou-se 2 e 1 plantas, respectivamente.

Trinta dias após o plantio, o material vegetal foi cortado, seco em estufa à $65^{\circ} \mathrm{C}$, pesado e moīdo. Para a de terminação do teor de fósforo na planta e a detecção da radioa tividade, procedeu-se à digestão nîtrico-perclórica de $500 \mathrm{mg}$ de material vegetal seco, completando-se no final o volume a $50 \mathrm{ml}$ em balões volumétricos.

Deste extrato, $20 \mathrm{ml}$ foram passados com o aux $\underline{\underline{T}}$ lio de pipetas volumétricas, para frascos apropriados nos quais se procedeu a deteç̧ão em um sistema de cintilação líquida Beckman LS-230, através do efeito Cerenkov.

Do restante do extrato, retirou-se uma aliquo ta conveniente, que foi diluída a $5 \mathrm{ml}$. Após a adição de $2 \mathrm{ml}$ 
da mistura em partes iguais das soluções de molibdato de amônio $5 \%$ e vanadato de amōnio $0,25 \%$, esperou-se 5 minutos e determinou-se a intensidade da cor em fotocolorímetro klett-sum merson 800-3, utilizando-se filtro azul (420 nm). Os teores de fósforo na planta foram encontrados por interpolação em uma curva obtida com padrões (LOTT et alii, 1956).

De posse dos resultados de atividade e teor de fósforo na planta, calculou-se o Valor L, segundo a equação 2, de RUSSELL et alii (1954), descontando-se o fósforo provenien te da semente.

A anālise estatistica dos resultados foi feita conforme PIMENTEL GOMES (1975).

4.3. VALOR E

4.3.1. InFLUẼNCIA DA CONCENTRA\&ÃO DA SOLUৎÃO CONTENDO ${ }^{31} P E{ }^{32} P$

Para este estudo, $5 \mathrm{~g}$ dos dois solos jā citados foram agitados em erlenmeyers $125 \mathrm{ml}$ de capacidade, devidamente arrolhados, com $50 \mathrm{ml}$ de uma solução contendo ${ }^{3 l} \mathrm{p}$ e $32 \mathrm{p}(0,5 \mathrm{ppm} ; 1 \mathrm{ppm} ; 2 \mathrm{ppm} ; 2,5 \mathrm{ppm} ; 4 \mathrm{ppm} ; 8 \mathrm{ppm} ; 16 \mathrm{ppm} ; 32$ ppm e 64 ppm P) e 1 gota de clorofórmio por 16 horas, em um a gitador horizontal de movimento circular, fazendo-se 2 repeti ções por concentração. 
Para este ensaio, as soluções de fósforo foram preparadas pela dissolução de $281,5 \mathrm{mg}$ de fosfato monobāsico de potássio, devidamente seco emestufa, em $1001 \mathrm{ml}$ de água des tilada, acrescentando-se antes de completar o volume, 1,425 $m C i$ de $32 p$, de forma que esta solução tivesse a concentração $64 \mathrm{ppm}$ P. A partir desta solução, por diluição, obteve-se as demais concentrações, garantindo-se assim que todas tivessem a mesma atividade específica.

Após a agitação, a solução era imediatamente se parada do solo, por filtração a vācuo, conforme estā apresentado na Figura 2.

Do extrato, $10 \mathrm{ml}$ foram passados com o auxîlio de pipetas volumétricas, para frascos apropriados, acrescen tando-se também $10 \mathrm{ml}$ de āgua destilada, procedendo-se então a deteç̧ão em um sistema de circulação líquida Beckman LS-230, atravēs do efeito Cerenkov.

Do restante do extrato, retirou-se uma alíquota de $4 \mathrm{ml}$, acrescentando-se $0,5 \mathrm{ml}$ de reativo sulfo-bismutomolíbdico e 0,5 ml de solução de ācido ascōrbico 6\%. Esperouse 30 minutos e determinou-se a intensidade da cor em fotocolorimetro klett-Summerson 800-3, utilizando-se filtro vermeTho $(660 \mathrm{~nm})$. A concentração de fósforo na solução foi encontrada por interpolação em uma curva obtida com padrões.

Durante todo o tempo em que as soluções foram agitadas com os solos, a temperatura manteve-se em torno de 
$20^{\circ} \mathrm{C}$

Com os resultados de atividade e concentração da solução, calculou-se o Valor E, segundo a equação 5 de RUS SELL et alii (1954).

A anālise estatística dos resultados foi feita conforme PIMENTEL GOMES (1975).

\subsection{IsOTERMAS DE ADSORGÃO}

4.4.1. InfluÊnCia do tempo de CONTATO SOLO-SOLŲÃO

Para este estudo, visando determinar o tempo de agitação necessāria para 4.4.2., $5 \mathrm{~g}$ dos dois solos jā citados foram agitados em erlenmeyers de $125 \mathrm{ml}$ de capacidade, de vidamente arrolhados, com $50 \mathrm{ml}$ de solução de fósforo $(0,5$ ppm;2,5 ppm; 8 ppm; 16 ppm e 64 ppm P) e 1 gota de clorofórmio, por vārios tempos (30 min; $1 \mathrm{~h} ; 2 \mathrm{~h} ; 4 \mathrm{~h} ; 8 \mathrm{~h} ; 16 \mathrm{~h} ; 24 \mathrm{~h}$ e $48 \mathrm{~h}$ ) em um agitador horizontal de movimento circular.

As soluções foram preparadas pela dissolução de $562,4 \mathrm{mg}$ de fosfato monobásico de potássio, seco em estufa, em 2 litros de ăgua destilada, de forma a ter-se a solução de con centração 64 ppm P, e, a partir desta solução, por diluição, obteve-se as demais soluções.

Após a agitação, a solução era imediatamente se parada do solo, por filtração a väcuo, conforme estā apresen- 
tado na Figura 2 .

Para determinar-se a concentração de fósforo nos extratos, utilizou-se o mētodo proposto por MURPHY e RILEY (1962), pelo qual, uma alíquota do extrato é retirada para tu bo de ensaio, e diluída, de forma que ao final se obtenha uma solução contendo no māximo a concentração 1 ppm P. A esta solução, adiciona-se a solução ācida de molibdato, que contém 20 g de molibdato de amōnio; $0,7 \mathrm{~g}$ de tartarato duplo de antimónio e potássio e $320 \mathrm{ml}$ de àcido sulfürico concentrado por lí tro, na proporção de $0,2 \mathrm{ml}$ por $5 \mathrm{ml}$ de volume final no tubo e $10 \mathrm{mg}$ de àcido ascōrbico, para esse volume final. Esperou se 30 minutos e fez-se a leitura da intensidade da cor em um espectrofotómetro Varian 634, utilizando-se o comprimento de onda $880 \mathrm{~nm}$, que oferece maior eficiência. A concentração de fósforo na solução foi encontrada por interpolação na curva ob tida com padrões.

\section{4,2. InfLUẼNCIA DA CONCENTRA\&ÃO INICIAL DA SOLUCÃO} Para este estudo, $5 \mathrm{~g}$ dos dois solos jā citados foram agitados em erlenmeyers de $125 \mathrm{ml}$ de capacidade, de vidamente arrolhados, com soluções de concentração inicial 0,5 ppm; 1 ppm; 2 ppm;2,5 ppm; 4 ppm; 8 ppm; 16 ppm; 32 ppm e 64 ppm $P$ e uma gota de clorofórmio, por 16 horas, em agitador ho rizontal de movimento circular. 
As soluções foram preparadas de forma idēntica às usadas em 4.4.1. e foram separadas do solo após a agita ção, como lá estā descrito e para a determinação da concentra ção dos extratos, utilizou-se tambēm o método MURPHY e RILEY (1962).

Com os resultados de concentração final e adsorção, traçou-se as isotermas de adsorção pelas fórmulas de Freundlich e Langmuir, calculando-se as constantes $n$, $K^{\prime}$, b e K dos dois solos.

Durante toda a agitação, nestes dois ensaios, a temperatura manteve-se tambēm em torno de $20^{\circ} \mathrm{C}$. 


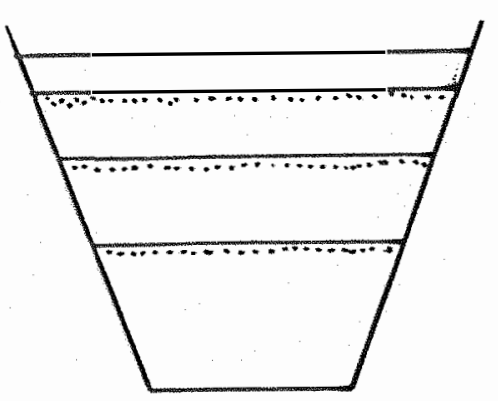

A

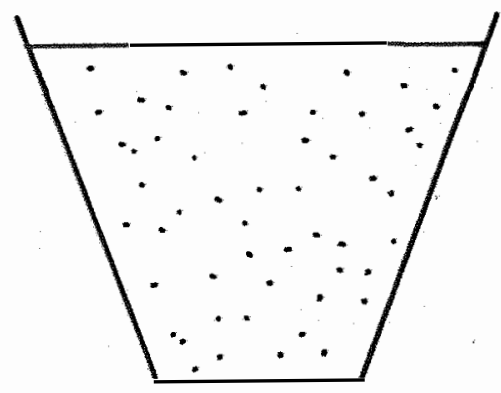

B

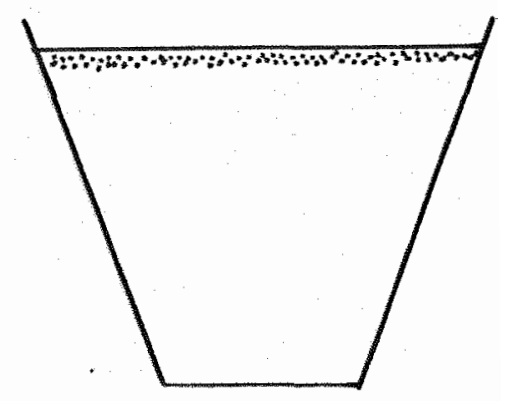

c

FIGURA 1 - Esquema de aplicação da solução contendo ${ }^{31} p$ e ${ }^{32 p}$ ao solo dos vasos: A - em camadas; B - mistura com o solo e C - na super fície.

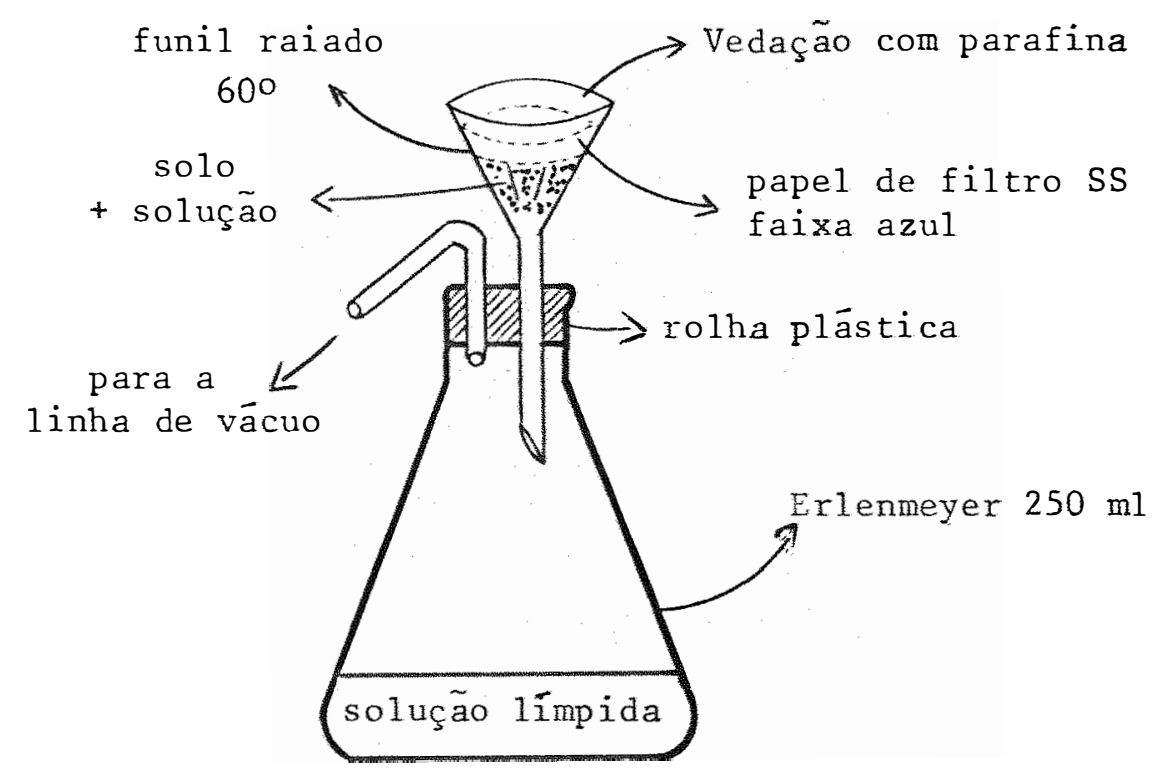

FIGURA 2 - Esquema da extração a vãcuo, da solução que foi agitada com o solo. 
5. RESULTADOS

5.1. Ensaios para a determinagão do Valor $L$

5.1.1. Produgão de Material Vegetal Seco $(M, V, S$, )

As quantidades, em gramas de material vegetal seco em estufa produzidas por quilograma de solo existente nos vasos, para os quatro ensaios, são apresentados na Tabela 2. A anālise de variāncia conjunta dos resultados, revelou serem significatos ao nivel de $1 \%$ de probabilidade, os efeitos de solos $(F=783,61)$, espécies $(F=745,55)$, doses $(F=452,38)$ e modos de aplicação $(F=19,09)$ e não significa tivo o efeito de quantidade de solo utilizado $(F=2,99)$.

0 teste de Tukey ao nivel de $1 \%$ de probabilida de, mostrou que a produção de M.V.S. foi significativamente di ferente entre o TE $(\bar{m}=1,26)$ e OPVp $(\bar{m}=0,767)$, entre ofei 
joeiro $(\bar{m}=1,26)$ e o mitho $(\hat{m}=0,773)$, entre a dose $25 \mathrm{mg} P$ $(\hat{m}=1,20)$ e a dose $5 \mathrm{mg} P(\hat{m}=0,827)$. Já para os modos de $\underline{a}$ plicação a $(\bar{m}=1,13), b(\bar{m}=0,959), c(\bar{m}=0,964)$ e d $(\bar{m}=1,01)$ e as quantidades de solo utilizado $1 \mathrm{~kg}(\overline{\mathrm{m}}=1,03)$, $3 \mathrm{~kg}(\overline{\mathrm{m}}=1,03)$ e $5 \mathrm{~kg}(\overline{\mathrm{m}}=0,984)$, as diferenças $n a \tilde{o}$ foram significativas. 


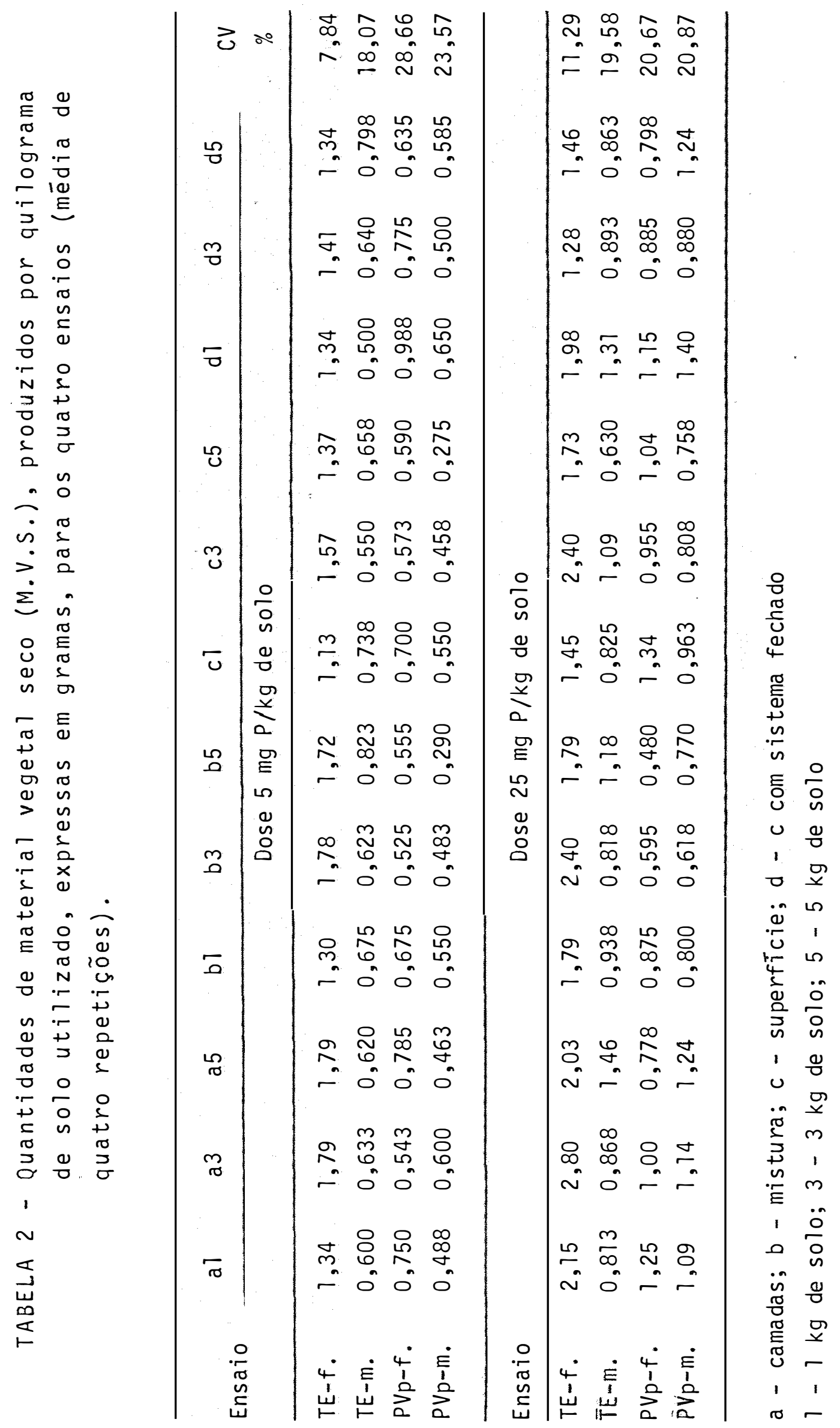




\subsubsection{ABSOR\&ÃO DE FÓSFORO PELA PLANTA}

As quantidades de fósforo absorvido, em miligramas por grama de M.V.S., para os quatro ensaios, aparecem na Tabela 3.

A anālise de variāncia conjunta dos resultados, mostrou serem significativos ao nível de $1 \%$ de probabilidade, os efeitos de solos $(F=390,19)$, espécies $(F=608,39)$, doses $(F=64,70)$, modos de aplicação $(F=15,61)$ e quantidade de solo utilizado $(F=5,85)$.

0 teste de Tukey ao nível de $1 \%$ de probabilida de, considerou significativas as diferenças de teores de fósforo absorvido entre o feijoeiro $(\bar{m}=1,71)$ e o milho $(\bar{m}=$. $1,06)$, entre o solo PVp $(\hat{m}=1,65)$ e o TE $(\bar{m}=1,13)$. Jà as diferenças entre a dose $25 \mathrm{mg} P(\overline{\mathrm{m}}=1,49)$ e a dose $5 \mathrm{mg} P(\overline{\mathrm{m}}=$ $1,28)$, entre os modos de aplicação a $(\bar{m}=1,51)$, b $(\hat{m}=1,44)$, $c(\bar{m}=1,30)$ e $d(\bar{m}=1,30)$ e entre as quantidades de solo uti1izado $1 \mathrm{~kg}(\hat{\mathrm{m}}=1,32), 3 \mathrm{~kg}(\overline{\mathrm{m}}=1,42)$ e $5 \mathrm{~kg}(\hat{\mathrm{m}}=1,42)$ não foram significativas. 
$\frac{1}{0}$

E

n

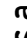$$
\text { n }
$$$$
\stackrel{1}{2}
$$$$
\text { aे w }
$$$$
\text { un }
$$$$
\therefore
$$$$
\text { i }
$$$$
>\quad 2
$$$$
\Sigma
$$

o

ס

E

का व

$\begin{array}{ll}2 & 0 \\ 0 & 0 \\ 2 & 0\end{array}$

N

0

$\Rightarrow \quad 0$

द

$\begin{array}{ll}0 & 0 \\ \text { un } & \text { u } \\ \text { 0 } & 0\end{array}$

$\begin{array}{cc}0 & 0 \\ 1 & 1 \\ 0 & 1 \\ 4 & 0 \\ 10 & 0 \\ 10 & 0\end{array}$

4

ㅇำ

$\begin{array}{ll}0 & 0 \\ 0 & 0 \\ 0 & 0 \\ 0 & 0 \\ 0 & n \\ + & n \\ + & 0 \\ 5 & E \\ 0 & 0 \\ 3 & 1 \\ 0 & 0\end{array}$

1
$m$
$w$
$\infty$
$\leftarrow$

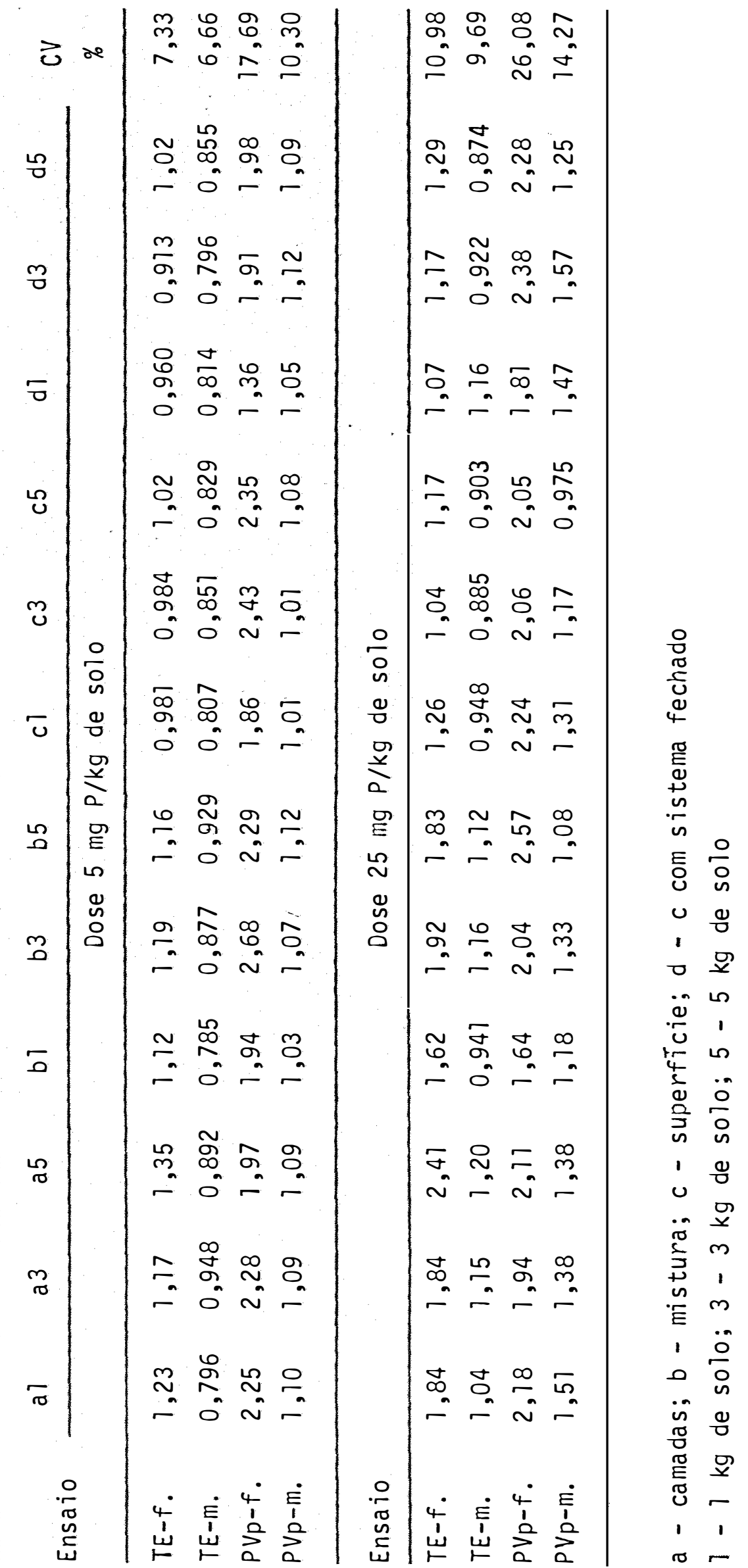




\subsubsection{Atividade específica na PLANTA}

As atividades específicas, em impulsos por minuto por miligrama de fósforo na planta foram transformados para $\sqrt{x+1}$ e são apresentadas, para os quatro ensaios, na Tabela 4.

Fez-se a anālise de variāncia conjunta dos qua tro ensaios, pois as atividades especificas transformadas dos padrões eram semelhantes $(111,28,105,86,108,77$ e 109,35 , res pectivamente). A análise de variāncia revelou serem significa tivos ao nível de $1 \%$ de probabilidade, os efeitos de solos(F= $1.251,45)$, espécies $(F=173,47)$, doses $(F=7.802,39)$, modos de aplicação $(F=378,57)$ e quantidade de solo utilizado $(F=$ $37,37)$.

0 teste de Tukey ao nível de $1 \%$ de probabilida de mostrou que as atividades especificas transformadas foram significativamente diferentes para a dose $25 \mathrm{mg} P(\overline{\mathrm{m}}=72,22)$ e a dose $5 \mathrm{mg} P(\bar{m}=34,29)$, para o modo de aplicação a ( $\overline{\mathrm{m}}=$ $65,74)$ e os demais modos de aplicação $\left(\hat{m}_{b}=49,67, \hat{m}_{c}=48,11\right.$, $\left.\widehat{m}_{d}=49,49\right)$. As diferenças foram significativas ao nível de $5 \%$ de probabilidade entre o TE $(\bar{m}=60,85)$ e $0 \operatorname{PVp}(\bar{m}=45,66)$ e não foram significativas entre o milho $(\bar{m}=56,08)$ e 0 feijoeiro $(\bar{m}=50,43)$ e entre as quantidades de solo utilizado $1 \mathrm{~kg}(\hat{\mathrm{m}}=55,32), 3 \mathrm{~kg}(\hat{\mathrm{m}}=53,38)$ e $5 \mathrm{~kg}(\hat{\mathrm{m}}=51,06)$. 


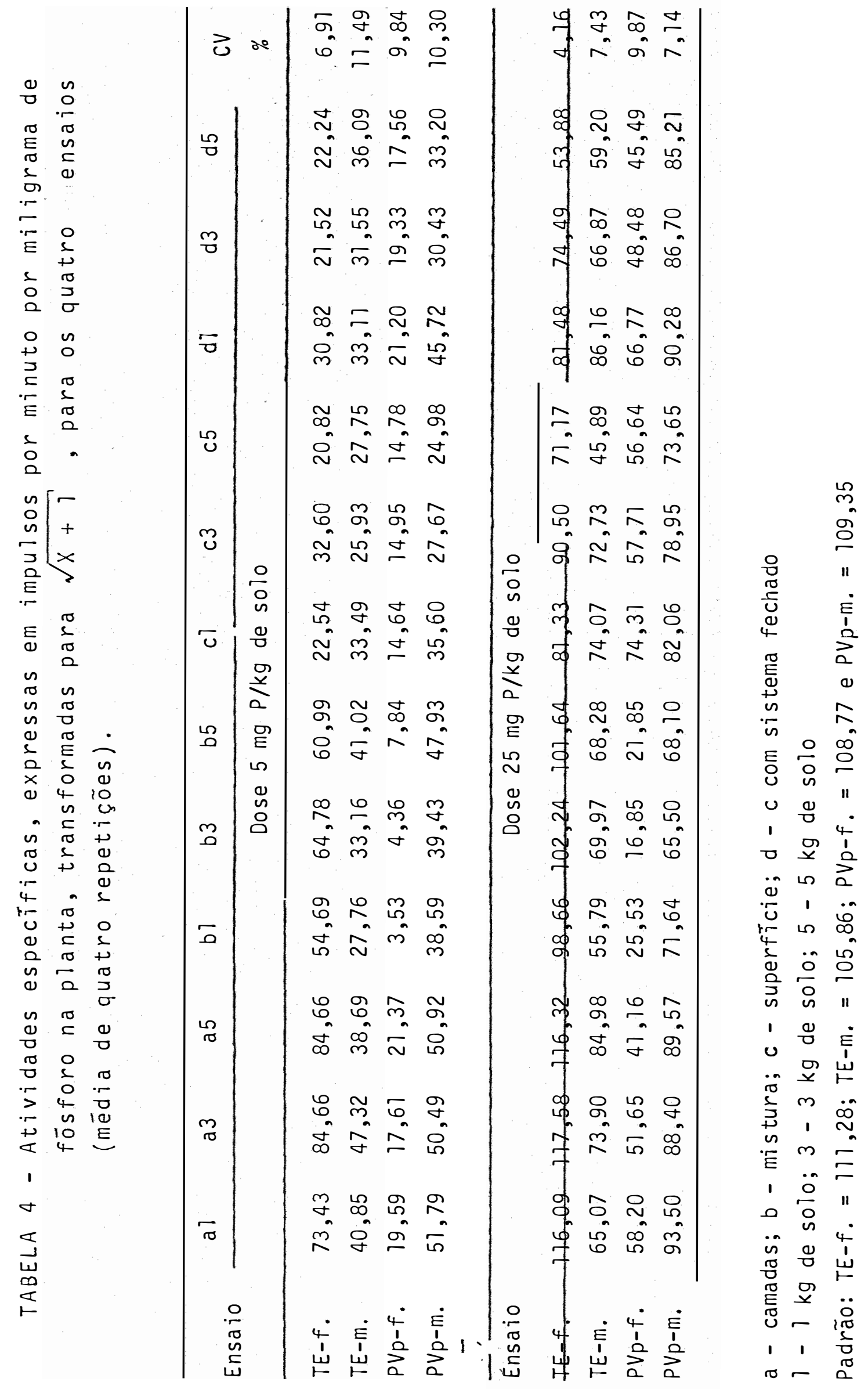




\subsubsection{CÁlCULO dO VALOR L}

Os Valores L calculados, em miligramas de fösro por quilograma de solo, para os quatro ensaios, são apre sentados na Tabela 5 .

A anālise de variāncia conjunta desses resulta dos revelou serem significativos ao nivel de $1 \%$ de probabilidade, os efeitos de solos $(F=3.639,96)$, éspécies $(F=$ $3.863,94)$, doses $(F=2.109,30)$, modos de aplicação $(F=$ 2.554,00) e quantidade de solo utilizado $(F=393,82)$.

0 teste de Tukey ao nível de $1 \%$ de probabilida de mostrou que eram significativas as diferenças entre PVp $(\hat{m}=222,25)$ e TE* $(\hat{m}=24,60)$, feijoeiro $(\hat{m}=225,25)$ e milho $(\hat{m}=21,60)$, dose $5 \mathrm{mg} P(\bar{m}=198,66)$ e dose $25 \mathrm{mg} P(\bar{m}=48,19)$, o modo de aplicação b $(\bar{m}=371,30)$ e os demais modos $\left(\hat{m}_{a}=\right.$ 27,$39 ; \hat{m}_{c}=52,25$ e $\widehat{m}_{d}=42,77$ ) e somente ao nível de $5 \%$ de probabilidade, os efeitos de quantidade de solo utilizada: 1 $\mathrm{kg}(\overline{\mathrm{m}}=116,08 \mathrm{ab}), 3 \mathrm{~kg}(\overline{\mathrm{m}}=183,04 \mathrm{a})$ e $5 \mathrm{~kg}(\overline{\mathrm{m}}=71,16 \mathrm{~b})$. Observando-se os Valores $L$ da Tabela 5 , nota se que no ensaio PVp-feijoeiro, para a dose $5 \mathrm{mg} P$ e modo de aplicação b, estes valores são muito maiores que os demais da Tabela e como no teste de Tukey, as médias foram maiores para essas variāveis, é possível que as mēdias estejam sendo muito afetadas por aqueles valores altos.

Para tirar essa dūvida, fez-se uma nova anālise de variāncia utilizando-se somente os modos de aplicação a, c e d, que revelou serem significativos ao nīvel de $1 \%$ de pró 
babilidade os efeitos de solos $(F=4.515,43)$, espécies $(F=$ $9.553,24)$, doses $(F=6.447,58)$, modos de aplicação $(F=855,81)$ e quantidade de solo utilizado $(F=721,44)$.

0 novo teste de Tukey revelou que somente as di ferenças entre feijoeiro $(\bar{m}=60,56)$ e milho $(\bar{m}=21,04)$ foram significativos ao nível de $5 \%$ de probabilidade, sendo não significativas as diferenças entre PVp $(\hat{m}=54,39)$ e TE $(\bar{m}=$ $27,22)$, dose $5 \mathrm{mg} P(\overline{\mathrm{m}}=56,82)$ e dose $25 \mathrm{mg} P(\overline{\mathrm{m}}=24,78), 0 \mathrm{~s}$ modos de aplicação a $(\bar{m}=27,39), c(\bar{m}=52,25)$ e d $(\bar{m}=42,77)$ e as quantidades de solo utilizado $1 \mathrm{~kg}(\overline{\mathrm{m}}=31,26), 3 \mathrm{~kg}(\overline{\mathrm{m}}=$ $41,07)$ e $5 \mathrm{~kg}(\overline{\mathrm{m}}=50,07)$. 


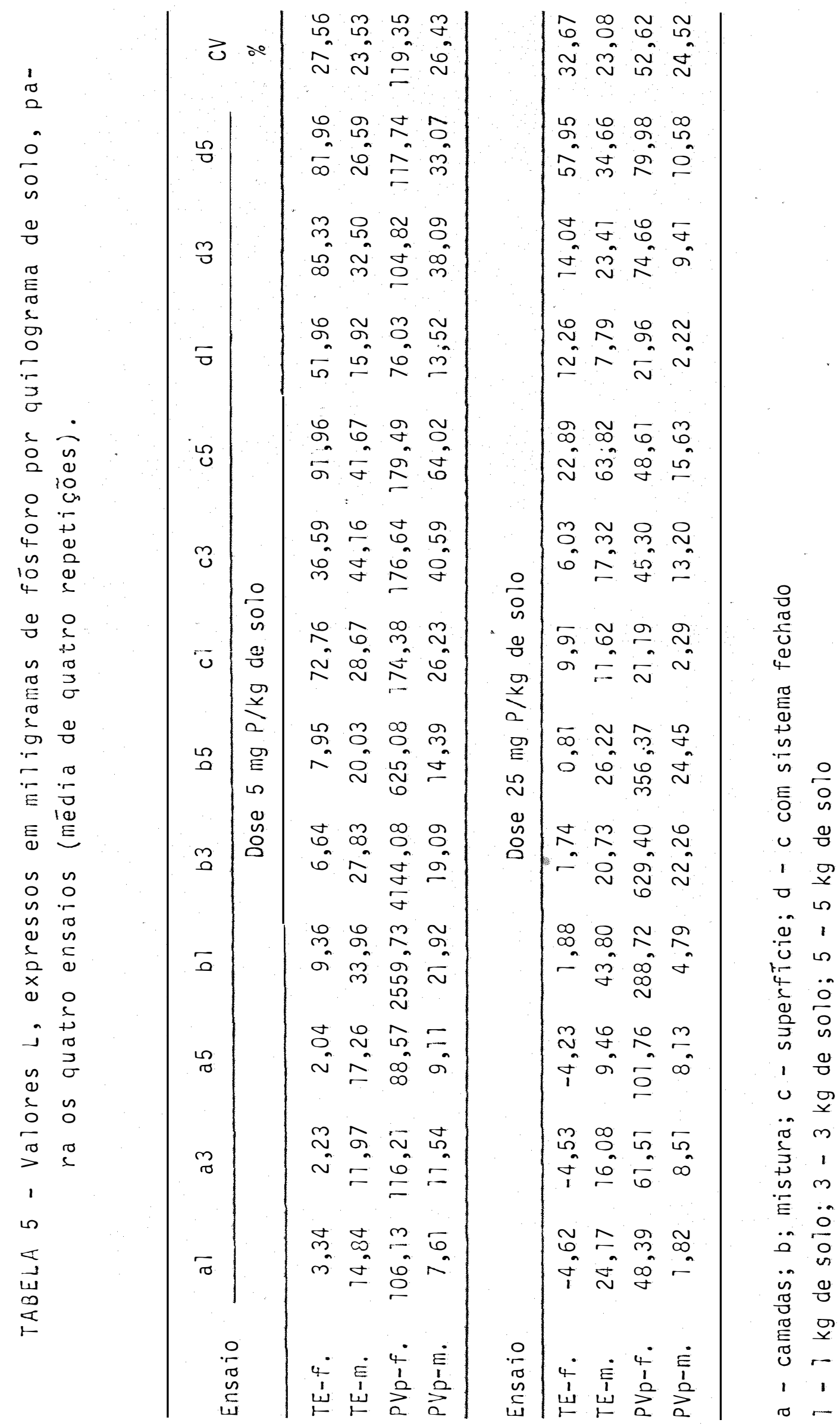


5.2. Ensaio para a determinagäo do VaLor E

Na Tabela 6 , são apresentadas as concentrações de fósforo e as atividades específicas das soluções, antes e depois de 16 horas de contato solo-solução, para os dois solos, bem como os resultados do cālculo do Valor E.

A anālise de variāncia dos resultados de Valor E mostrou ser significativo ao nível de $1 \%$ de probabilidade 0 efeito de concentração $(F=21,82)$ e não significativo o efei to de solos $(F=0,52)$.

0 teste de Tukey mostrou que foram significati vas ao nivel de $5 \%$ de probabilidade as diferenças entre a con centração 4 ppm $(\bar{m}=512,40)$, a concentração 8 ppm $(\bar{m}=280,29)$ e as demais concentrações $\left(\hat{m}_{1}=191,60 ; \hat{m}_{0,5}=183,35 ; \hat{m}_{2}=\right.$ 178,$\left.48 ; \hat{m}_{16}=108,05 ; \hat{m}_{25}=52,87 ; \hat{m}_{64}=43,71 ; \hat{m}_{32}=32,22\right)$. 0 solo TE $(\hat{m}=184,42)$ não diferiu do solo PVp $(\hat{m}=168,69)$. 


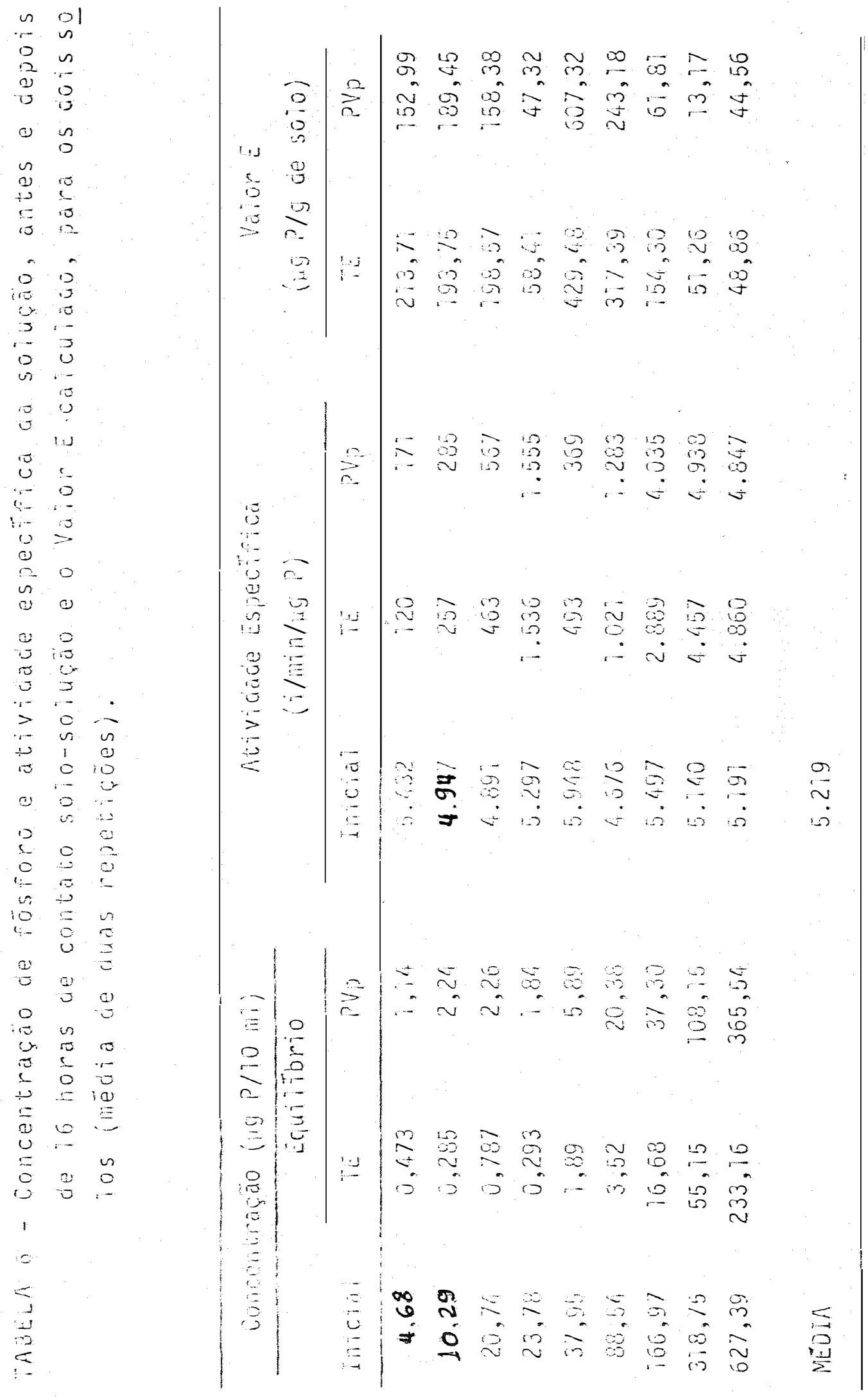




\subsection{ISOTERMAS DE ADSORgẼo}

5.3.1. InfluÉnCiA do teitpo de CONTATO SOLO-SOLUs ÃO As concentrações de fósforo na solução, apōs a agitação, são apresentados na Tabela 7.

De posse desses resultados, calculou-se as quan tidades adsorvidas (X/M) e construiu-se o grăfico dafigura 3. Verifica-se que 16 horas de agitação eram suficientes paraque o equilíbrio fosse atingido para soluções com até 16 ppm e 3 ppm para os solos TE e PVp, respectivamente.

Como as concentrações que rais nos interessam

são as de 0,5 e $2,5 \mathrm{ppm}$, una vez que elas correspondem às doses 5 e $25 \mathrm{mg} P / \mathrm{kg}$ de sole utilizadas no Vator $\mathrm{L}$ e que serão comparadas, optou-se por 16 horas de agitação para a determinação do Valor E e da isoterma de âdsorção. 
TABELA 7 - Concentração de fösforo na solução, expressa emug/ ml, para cinco concentrações iniciais da solução, com vārios tempos de contato do sistema solo-solução, nos dois solos.

\begin{tabular}{|c|c|c|c|c|c|}
\hline \multirow{3}{*}{$\begin{array}{c}\text { Tempo } \\
(h)\end{array}$} & \multicolumn{5}{|c|}{ Concentração Inicial (ug P/ml) } \\
\hline & 0,5 & 2,5 & 8 & 16 & 64 \\
\hline & \multicolumn{5}{|c|}{ TE } \\
\hline $\begin{array}{l}0 \\
1 / 2 \\
1 \\
2 \\
4 \\
8 \\
16 \\
24 \\
48\end{array}$ & $\begin{array}{l}0,493 \\
0,049 \\
0,021 \\
0,029 \\
0,029 \\
0,031 \\
0,042 \\
0,025 \\
0,082\end{array}$ & $\begin{array}{l}2,50 \\
0,222 \\
0,144 \\
0,185 \\
0,081 \\
0,048 \\
0,033 \\
0,048 \\
0,059\end{array}$ & $\begin{array}{l}7,92 \\
1,98 \\
1,17 \\
0,897 \\
0,552 \\
0,325 \\
0,335 \\
0,247 \\
0,197\end{array}$ & $\begin{array}{r}15,94 \\
6,27 \\
4,64 \\
3,93 \\
2,72 \\
1,89 \\
1,45 \\
1,18 \\
1,06\end{array}$ & $\begin{array}{l}64,09 \\
43,29 \\
36,68 \\
34,41 \\
29,58 \\
27,91 \\
26,72 \\
23,07 \\
23,77\end{array}$ \\
\hline & \multicolumn{5}{|c|}{$P \vee p$} \\
\hline $\begin{array}{c}0 \\
1 / 2 \\
1 \\
2 \\
4 \\
8 \\
16 \\
24 \\
48\end{array}$ & $\begin{array}{l}0,493 \\
0,222 \\
0,196 \\
0,1917 \\
0,216 \\
0,260 \\
0,708 \\
0,103 \\
0,133\end{array}$ & $\begin{array}{l}2,50 \\
0,910 \\
0,788 \\
0,610 \\
0,470 \\
0,551 \\
0,362 \\
0,237 \\
0,302\end{array}$ & $\begin{array}{l}7,92 \\
3,97 \\
3,51 \\
2,71 \\
2,45 \\
1,82 \\
1,66 \\
1,34 \\
0,838\end{array}$ & $\begin{array}{r}15,94 \\
10,41 \\
9,14 \\
7,60 \\
7,16 \\
5,83 \\
5,30 \\
4,56 \\
3,17\end{array}$ & $\begin{array}{l}64,09 \\
53,54 \\
52,26 \\
47,82 \\
47,73 \\
44,87 \\
40,53 \\
38,85 \\
38,55\end{array}$ \\
\hline
\end{tabular}




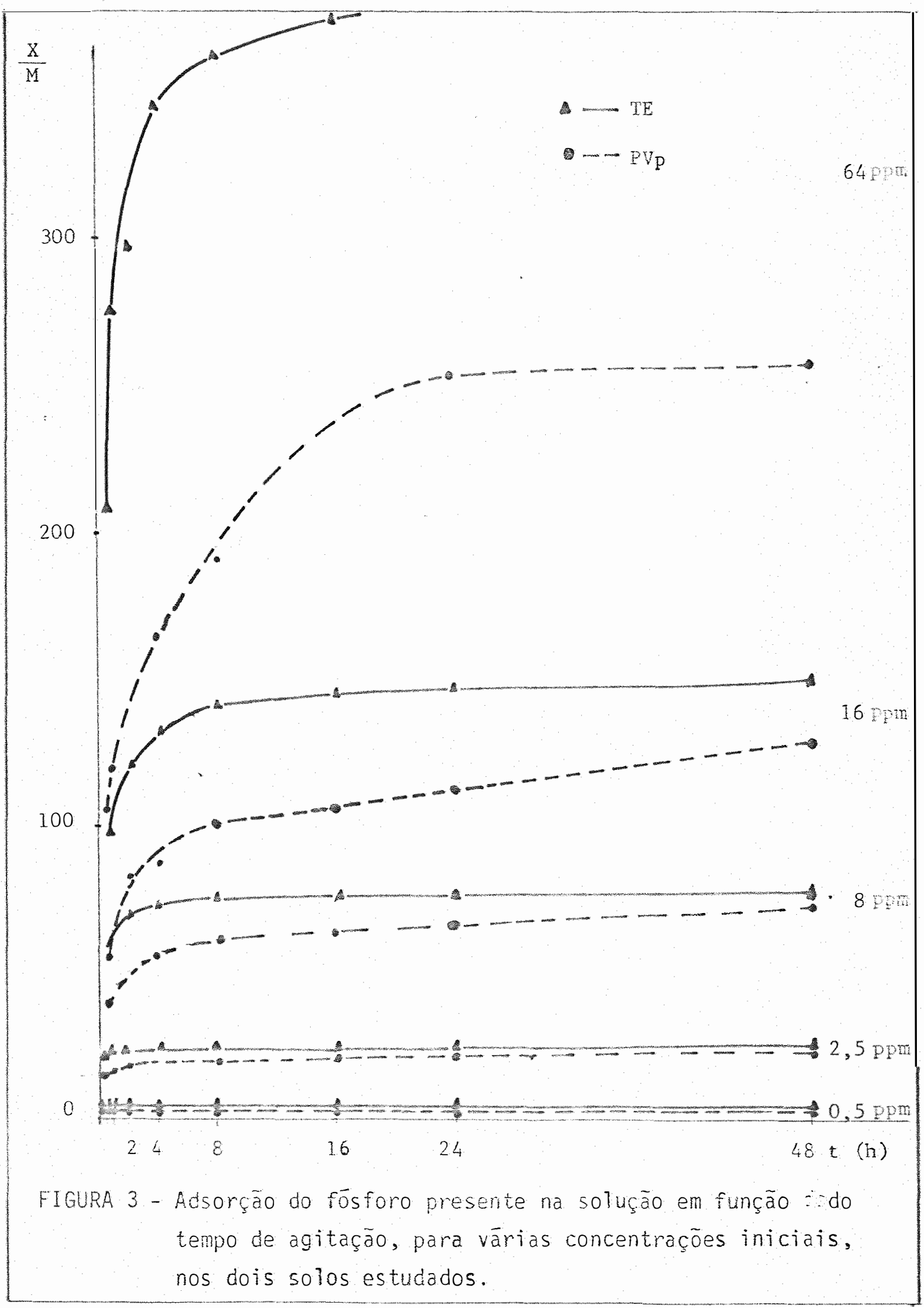


5.3.2. INFLUÉNCIA DA CONCENTRAGÃO INICIAL DA SOLUGÃO Os resultados de concentração de fósforo na so 1 ução apōs 16 horas de agitação, para os dois solos, estão na Tabela 8.

Calculou-se o fósforo adsorvido e traçou-se as isotermas de Freundlich e Langmuir, que aparecem nas Figuras 4 e 5 .

Pelas isotermas, calculou-se os valores de $n$, $K^{\prime}$, b e K, que para, o solo TE foram 0,534; 82,447; 204,876 $\mathrm{\mu g}$ $\mathrm{P} / \mathrm{kg}$ de solo e $1,801 \mathrm{ml} / \mathrm{gg}$, respectivamente e para 0 solo

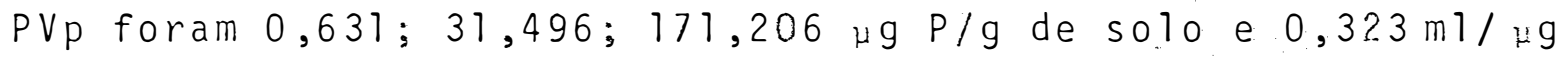
$P$, respectivamente.

TABELA 8 - Concentração de fósforo na solução, expressa em $\mu \mathrm{g} / \mathrm{ml}$, após 16 horas de contato solo-solução, para diversas concentrações iniciais, nos dois solos.

\begin{tabular}{ccc}
\hline $\begin{array}{c}\text { Concentração Inicial } \\
(\mu \mathrm{P} / \mathrm{ml})\end{array}$ & \multicolumn{2}{c}{ Solos } \\
\cline { 2 - 3 } 0,493 & 0,042 & PVp \\
0,992 & 0,027 & 0,108 \\
2,02 & 0,047 & 0,153 \\
2,50 & 0,033 & 0,267 \\
3,93 & 0,168 & 0,362 \\
7,92 & 0,335 & 0,710 \\
15,94 & 1,45 & 1,66 \\
32,15 & 6,41 & 5,30 \\
64,09 & 26,72 & 16,07 \\
\hline
\end{tabular}




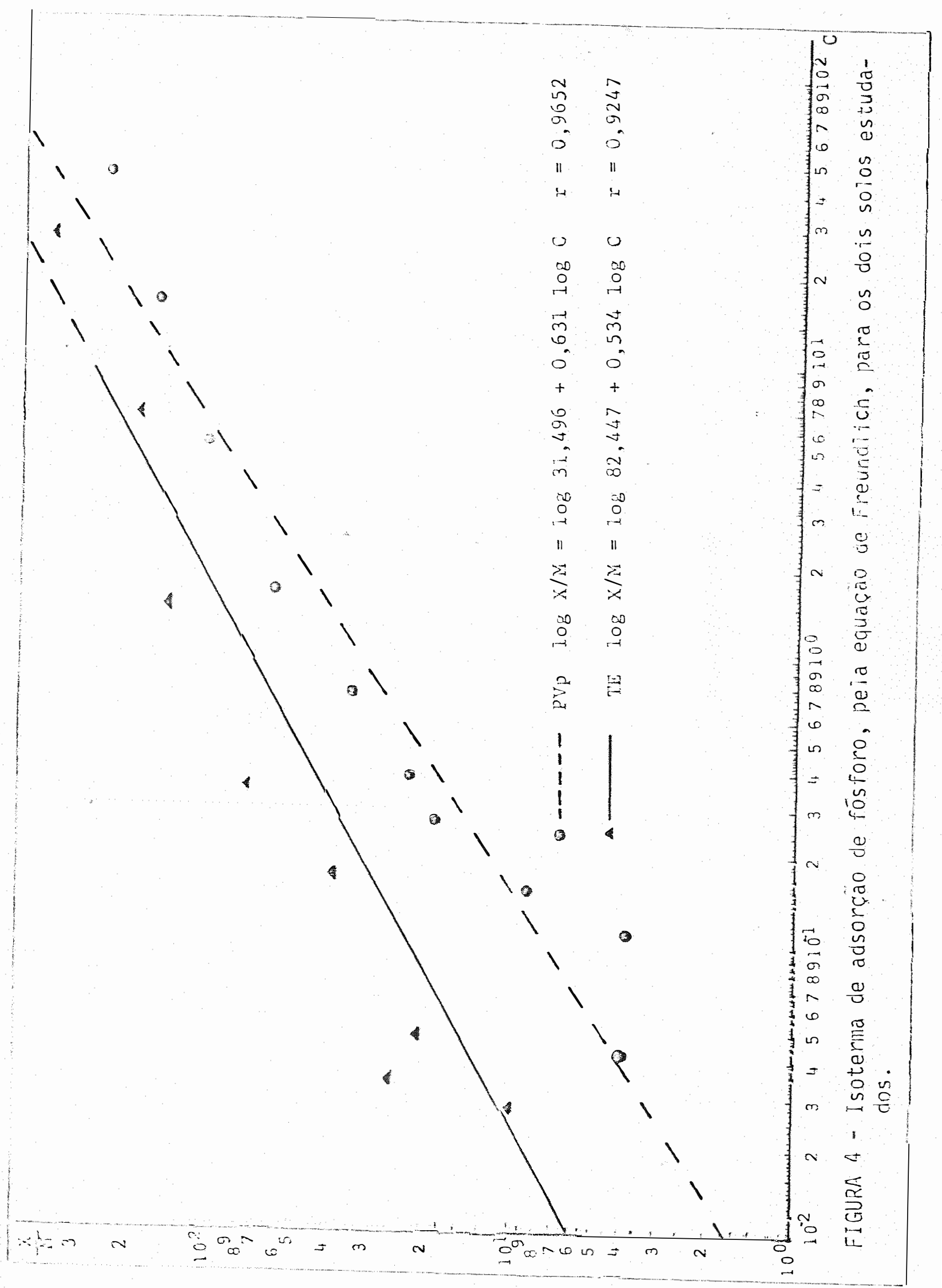




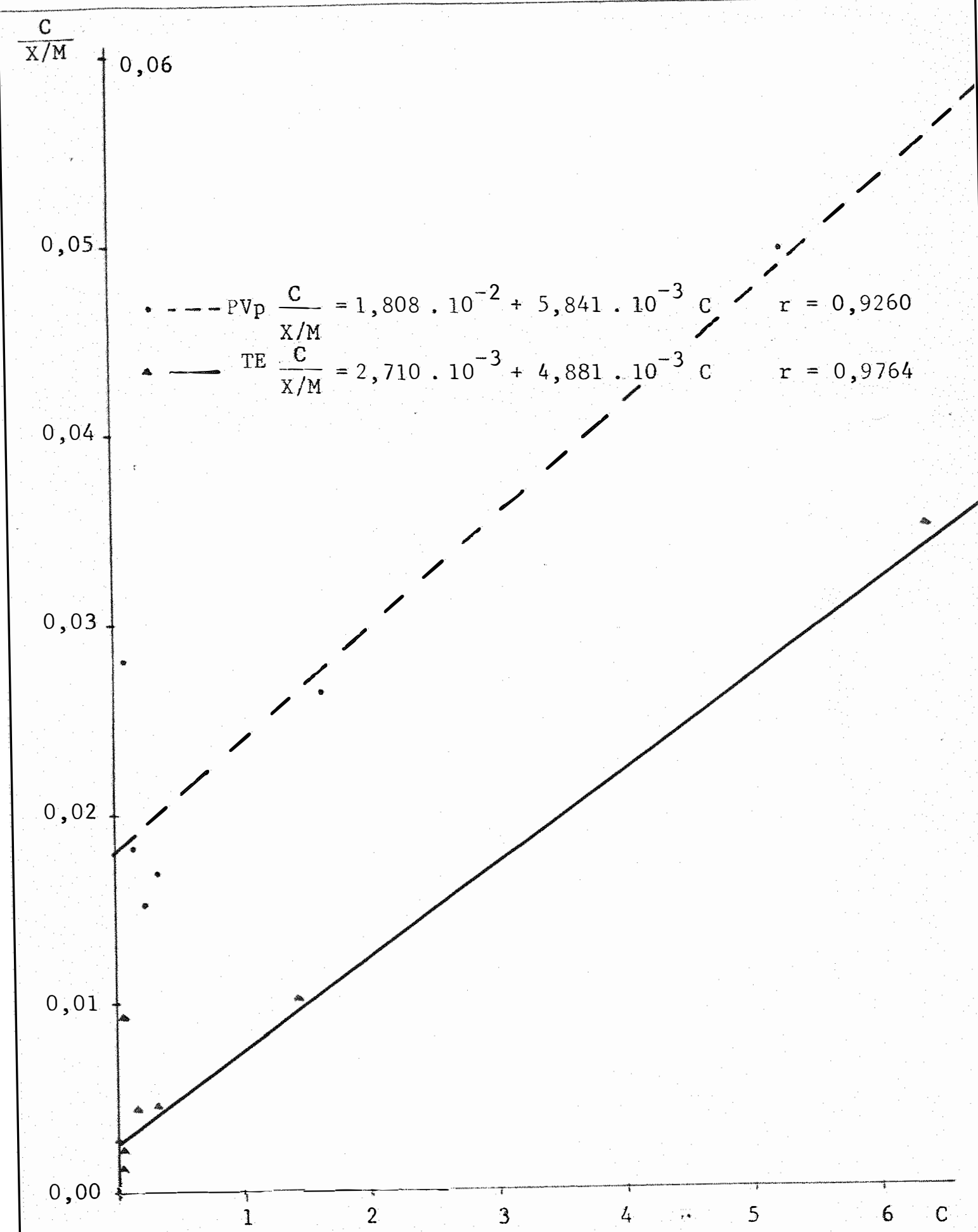

FIGURA 5 - Isoterma de adsorção de fósforo, pela equação de Langmuir, para os dois solos estudados. 
6. DISCUSSÃO

Nos ensaios para a determinação do Valor L, a produção de M.V.S. (Tabela 2) foi diferente para as duas espé cies, prevalecendo quase sempre o feijoeiro sobre o milho. Es se efeito, talvez se deva ao fato de ter-se duas plantas de feijoeiro e uma de milho, pois quando se divide a produção do feijoeiro por dois, temos resultados praticamente equivalen tes para as duas espécies. Manteve-se um nūmero diferente de plantas, esperando-se que as produções fossem equivalentes, mas tal não aconteceu.

Para as duas doses, como era de se esperar,pre valeceu sempre a dose de $25 \mathrm{mg}$ P, mas a produção de M.V.S. ser maior para o solo TE surpreendeu, uma vez que o fósforo soluvel $\bar{e}$ menor que no solo PVp. E possível justificar esse fato, observando-se o teor total desse elemento nos dois solos. De fato, a reserva de fósforo no solo TE $\bar{e}$ bem maior que a do so 10 PVP. 
Já os modos de aplicação e as quantidades de so ¿lo, praticamente não afetaram a produção de M.V.S., podendo se supor, que a mesma quantidade de nutrientes esteveà dis posição das plantas.

Para as quantidades de fósforo por grama de M.V.S. (Tabela 3), das espécies, a que prevaleceu foi o feijoeiro, da mesma forma que para produção, por que essa planta deve acumular mais fósforo que o milho, nesse estāgio de desenvolvimento. Dos solos, o PVp proporcionou maiores quantida des de fósforo na planta, mostrando um nitido efeito de dilui ção, ou seja, às maiores produções de M.V.S., correspondem as menores quantidades do elemento.

Jà as doses de fósforo, os modos de aplicação e as quantidades de solo, não afetaram as quantidades de fósforo na planta.

Quando se multiplica a produção de M.V.S. (g/ kg de solo) pelas quantidades de fósforo contidas no M.V.S. (mg $P / g)$, nota-se que a absorção de fósforo, em mg P/kg de so 10, para o solo TE $(\hat{m}=1,49)$ e para o solo PVp $(\hat{m}=1,30)$, pra ticamente não diferem, acontencendo o mesmo para as quantidades de solo $\left(\bar{m}_{1}=2,91, \bar{m}_{3}=2,89\right.$ e $\left.\bar{m}_{5}=2,82\right)$.

Por outro lado, para as doses $\left(\overline{\mathrm{m}}_{5}=1,03\right.$ e $\overline{\mathrm{m}}_{25}=$ $1,76)$, as espécies $\left(\bar{m}_{f}=2,00\right.$ e $\left.\bar{m}_{m}=0,788\right)$ e os modos de aplicação $\left(\hat{m}_{a}=1,83, \hat{m}_{b}=1,39, \hat{m}_{c}=1,24\right.$ e $\left.\hat{m}_{d}=1,29\right)$, os re sultados são diferentes, mostrando que para os dois solos e as trés quantidades de solo, as plantas conseguiram absorver pra 
ticamente a mesma quantidade de fósforo, mas o feijoeiro extraiu mais que o milho, talvez devido ao efeito do número de plantas jā mencionado.

As plantas responderam ãs doses aplicadas, absorvendo mais da dose maior. Para os modos de aplicação, nota-se que a localização do fósforo em camadas, possibilitou um aumento de absorção desse nutriente, vindo a seguir os demais modos de aplicação. Destes, mistura com todo o solo foi o que promoveu maior absorção e as aplicações em superfície não diferiram entre si, evidenciando que a ausēnciadedrenagem "não afetou a absorção de fósforo.

No que diz respeito às atividades específicas na planta (Tabela 4), as plantas mostraram resposta ãs doses, prevalecendo a dose de $25 \mathrm{mg} P$. A aplicação em camadas, promo veu maiores atividades específicas, que os demais modos de aplicação, não diferindo entre si as aplicações em superfície, evidenciando que a drenagem não afetou a absorção de ${ }^{31} p$ e ${ }^{32 p}$ pelas plantas. Observa-se ainda um pequeno efeito dos solos e nenhum efeito das espécies e quantidades de solo.

Quándo se calculou o Valor L, observou-se de $\underline{u}$ ma maneira geral, uma inversão nas tendēncias, uma vez que no tratamento onde a atividade específica é maior, houve uma menor diluição isotōpica, e conseqüentemente, o Valor L calcula do é menor.

Para o ensaio PVp-feijoeiro (Tabela 5 ), no modo de aplicação-mistura com todo o solo, os Valores L calcula 
dos são muito altos, quando comparados com os outros modos de aplicação, para as duas doses de fōsforo aplicadas. As atividades especîficas naquele modo de aplicação eram muito pequenas e o alto coeficiente de variação dos Valores L deste ensaio é devido principalmente a este modo de aplicação.

Para que a añ̄ise dos resultados não ficasse afetada por aqueles valores altos, lançou-se mão da eliminação dos resultados do modo de aplicação mistura com todo o so 10, de todos os ensaios, mas perdeu-se assim a informação do comportamento desse modo de aplicação.

Visando recuperar essa informação, eliminou-se os resultados do ensaio PVp-feijoeiro da anālise, e assim, ob tivemos a seguinte seqüencia de modos de aplicação: superfície com drenagem $(\hat{m}=33,86)$, superfície sem drenagem $(\bar{m}=$ $30,69)$, mistura com todo o solo $(\hat{m}=17,11)$ e em camadas $(\hat{m}=$ 7,49). Como era de se esperar, esta sequência é inversa à obtida com as atividades específicas.

No ensaio TE-feijoeiro, para a dose $25 \mathrm{mg}$ P, 0 cáiculo do valor L resultou em valores negativos. Analisandose à equação 1, nota-se que o Valor L será negativo, somente se a relação entre a atividade especîfica da solução adicionada e a ativiciade específica na planta for menor que 1. Para que is so aconteça, a atividade específica na planta deve ser maior que a da solução adicionada, o que realmente ocorre e é obser vado na Tabela 4.

Valor L negativo jā foi encontrado por nōs e os 
colegas, em aula prätica da disciplina Uso de Isötopos em Qữ mica, Física e Fertilidade do Solo, na determinação desse va1or. Outros colegas, estagiārios do Setor de Fertilizantes e Fertilidade do Solo do CENA, determinando o Valor L, encontra ram resultados negativos (dados não publicados). Os valores ne gativos têm sido encontrados, quando se trabalha com solos de a.1 ta capacidade de adsorção e doses elevadas de carregador. LARSEN (1952), apōs submeter à 1ixiviação, um solo com valor pH $=6,5$, em coluna, onde havia sido colocadana superfície uma solução contendo $31 p$ e $32 p$ de atividade especî fica conhecida, observou que $0{ }^{32}$ p se acumulou na superfície, sendo sua proporção, maior que a de ${ }^{31} \mathrm{p}$, e que a partir de dois centimetros de profundidade, 31 p passava a predominar.

Esse comportamento diferente dos dois isōtopos, promoveria uma atividade especifica maior que a colocada, no local da aplicação, a qual iria diminuindo, à medida que a pro fundidade aumentasse.

o solo TE estava com o valor $\mathrm{pH}=6,4$, que $\vec{e}$ bem próximo ao pH do solo utilizado por LARSEN (1952), o que não ocorre com o solo pVp $(p H=5,0)$. A aplicação foi em trés camadas, e provávelmente, cada uma gerou um gradiente de atividades específicas, muitas delas maiores que a da solução adicionada. Se a planta absorveu mais fösforo em uma região on de a atividade especifica era mais alta, o M.V.S. teria ativi dade específica maior que o padrão, e conseqüentemente, os Va 1ores L seriam negativos. 
Se realmente foi assim que tudo aconteceu, por que ocorreu somente com o feijoeiro? Para tentar justificar, tomaremos por base, os resultados de atividade específica (Ta bela 4), para a localização em superfície. Pode-se notar, que para o milho, elas são sempre mais elevadas que para o feijoeiro, e é de se supor, que as raízes do milho, nesse estágio de desenvolvimento, absorveram mais $32 p$ que as do feijoei ro, e como a solução foi colocada na superfície do solo, o mi Tho deve ter absorvido fósforo, predominantemente dos cinco centimetros superiores do vaso, ao passo que o feijoeiro deve ter explorado regiões mais profundas. Do mesmo modo, para a localizasão em camadas, o feijoeiro deve ter retiradomais fós foro das trés camadas, que o milho, e portanto absorvido mais $32 \mathrm{P}$.

Por que os valores negativos não foram observa dos para a dose de $5 \mathrm{mg}$ P? Para a dose de fósforo menor, è de esperar, que coisa semelhante deve ter ocorrido, mas em escala menor, e este efeito deve ter sido neutralizado pela dilui çäo, dentro da planta, com o fósforo do solo.

os valores mais altos, podem ser justificados

pela fixação, ou pela utilização de apenas parte do fósforo a dicionado, mas para a localização em superfície, a justificativa seria, que as raízes das plantas exploram a camada super ficial, mas a superfície, onde a solução foi colocada e o $32 p$ deve ter se acumulado é pouco explorada, por ser muito instável cujeita ao secamento, durante certa fase do dia. Isso é 
mais evidente, na dose menor de fósforo.

LARSEN (1952) recomendou que o fósforo deveria ser aplicado em solução e misturado com todo o solo, para favorecer a troca isotópica, mas esse modo de aplicação produziu alguns valores altos, que podem ser justificados pela fixașão do fósforo, uma vez que os dois solos possuem elevadas adsorsōes máximas, calculadas pela isoterma de Langmuir (Figu ra 5 ).

A localização em camadas foi introduzida nos ensaios, a fim de possibilitiar um bom contato entre o solo e a solução e favorecer menos a fixação do fósforo. os valores que mais se aproximam dos encontrados na anälise química para avaliar a fertilidade, são os calculados para esse modo de aplicasão, embora, para o ensaio TE-feijoeiro, para as duas doses de fósforo, os resultados calculados para mistura com todo o solo, tambēm são prōximos daqueles.

LARSEN e SUTTON (1963) estudaram a influência do volume de solo utilizado, sobre o Valor L e encontraramque houve maior absorção de fósforo e os resultados do Valor L fo ram maiores para os vasos de tamanho menor. ANDERSEN et azi (1961) determinaram alguns fatores que influenciam os resulta dos do Valor l e afirmam que ele aumenta durante o crescimento e encontraram tendēncia semelhante quanto a tamanho dos va sos. Nossos resultados mostram uma tendēncia diferente para Valor 1. uma vez que os valores mais altos são encontrados nas maiores quantidades de solo. Quando à absorção de fósforo,nos 
sos resultados concordam com aqueles autores.

ANDERSEN e MOGENSEN (1963) encontraramboas cor relações entre o Valor L e a produção de M.V.S., utilizandova sos pequenos, e correlacionaram o Valor L com värios extratores quimicos, encontrando a seguinte ordem decrescente de cor relação: 0,5M carbonato ácido de sōdio, zeōlita sōdica, solução $A L$, potencial de fósforo, $0,2 \mathrm{~N}$ äcido sulfürico e $0,01 \mathrm{M}$ clo reto de cālcio. Nossos resultados mostram tendēncia inversa para produção de M.V.S. e Valor L, discordando daqueles autores.

SUTTON e LARSEN (1963), estudando o efeito residual de fertilizantes fosfatados, observaram grande correla ção entre absorção de fósforo pelo azevēm e o Valor L. Nossos ensaios mostram tendēncia inversa entre absorção de fósforo e Valor L, uma vez que a absorção do nutriente seguiu a ativida de especifica na planta.

RUSSELL et alii (1958) obtiveram diferenças sig nificativas entre os Valores L obtidos com cevada e repolho. Para o feijoeiro e o milho, as diferenças também foram significativas, mostrando o efeito da espécie utilizada sobre o va lor calculado.

No ensaio para a determinação do Valor E, a con centração e a atividade especîfica iniciais foram determina das nas soluções que foram adicionadas à porção de solo. Notase que às concentrações variam em torno das desejadas. Para as atividades especîficas, as variações são devidas à probabili- 
dade de detecção da radiação. Para as soluções de 4 e 8 ppm P, elas estão abaixo e acima, respectivamente, do intervalo de confiança da média, que vai de 4.871 a $5.579 \mathrm{i} / \mathrm{min} / \mu \mathrm{g} P$.

Os Valores E calculados, que nos interessam mais são os de 0,5 e 2,5 ppm $P$ na solução inicial, pois correspondem aos Valores $L$ nas doses de 5 e $25 \mathrm{mg} P$, respectivamente.

Comparando-se os resultados dos dois valores ( $L$ e E), nota-se uma tendēncia de serem mais baixos quando usou-se a dose $25 \mathrm{mg} P$ e para o solo PVp, porém os valores são muito diferentes.

Por outro lado, ANDERSEN e MOGENSEN (1963) encontraram boas correlações entre os Valores E e L. McConAGHY et azii (1967) encontraram correlações entre os valores, mas o grau de correlação foi menor que dos outros autores. RUSSELL et alii (1958) conseguiram correlações excelentes entre os dois valores, para as duas espécies estudadas.

As adsorções māximas calculadas pela isoterma de Langmuir mostram que o solo TE tem maior capacidade de adsorção, o que era de se esperar, pelos resultados da anāifse quimica dos teores totais (Tabela 1), uma vez que ele é rico em óxidos de Fe, Al e Ti.

Comparando-se os resultados das determinações dos Valores $E$ e $L$, e as isotermas de adsorção, nota-se que o solo com maior capacidade de adsorção, é também o que acusa maior quantidade de fósforo isotopicamente trocāvel, embora o 
fósforo extraỉdo com solução $0,05 \mathrm{~N}$ àcido sülfürico seja menor para esse solo. Com relação à quantidade de fósforo absorvido pelas plantas, ela foi maior para o TE, concordando com o acima discutido.

Maior discussão sobre esse tópico pode deixar a desejar, uma vez que a velocidade de dessorção desses solos não foi determinada, podendo-se tratar de um fenómeno particu lar do solo em questão.

Apesar dos inümeros trabalhos com os Valores $E$ e L, a discussão permanece num plano teōrico, uma vez que não existe uma calibração desses valores, que permita afirmar se um solo com um determinado valor L ou E é rico ou pobre emfós foro, mostrando que falta ainda pesquisar mais detalhes desses métodos. 


\section{CONCLUSÕES}

Com base nos resultados deste trabalho, podemos concluir que:

1 - os Valores L obtidos com os modos de aplicação em camadas e mistura homogénea com o solo, com a dose menor de fósforo e com a quantidade de solo maior, sãoos que mais se aproximam dos valores obtidos com extratores químicos.

2 - os Valores L obtidos para as duas espécies e para os dois solos são diferentes.

3 - os Valores E e L obtidos são diferentes.

4 - à maior capacidade de adsorção do solo TE, correspondem Valores L e E maiores, verificando-se o contrārio para o solo PVP.

5 - a drenagem não afetou o Valor L. 
8. SUMPARY

In two soils named Terra Roxa Estruturada (TE) and Podzōlico Vermelho Amarelo variação Piracicaba (PVp), some factors which should affect the results of the $L$ Value determination, were studied. These results were compared with those of the $E$ Value and the adsorption isotherms of Freundlich and Langmuir.

These factors were the following: 1) platspecies (bean-Phaseozus vulgaris L. and corn-zea mays L.); 2) levels of phosphorus (5 mg and $25 \mathrm{mg} / \mathrm{kg}$ of soil) with the same spe cific activity; 3) quantities of soil ( $1 \mathrm{~kg}, 3 \mathrm{~kg}$ and $5 \mathrm{~kg}$ ); 4) phosphorus placements (in layers, in mixture with the soil, in surface and in surface with closed system).

According to the data, the following conclusions can be drawn: 1) the L Values obtained with the placements in layers and in mixture with the soils, with the lower phosphorus level and with the higher quantity of soil, are 
more proximate of those obtained with chemical extractants; 2) the L Values obtained for both species and both soils are different; 3 ) the $E$ and $L$ Values are different; 4) to the higher adsorption capacity of the TE soil correspond higher E and $L$ Values and the opposite situation occurs with the PVp soil; 5) the drainage don't affect the L Value. 


\section{LITERATURA CITADA}

AMER, F.; D.R. BOUDIN; C.A. BLACK; F.R. DUKE, 1955. Characte rization of soil phosphorus by anion exchange resin adsorp tion and $32 p$ equilibration. Plant and Soil. The Hague, VI : $391-408$.

AMER, F., 1962. Determination of $32 p$ exchangeable phosphorus in soils. IN: IAEA/FAO. Symposium of radioisotopes in soil. and plant nutrition studies. Viena: 43-58.

ANDERSEN, J.; B. GREGERS-HANSEN; G. NIELSEN, 1961. Determination of the phosphate condition of soils by means of radioactive phosphorus in pot experiments. Acta Agric. Scand. Stockholm, XI: $270-290$.

ANDERSEN, J. e Th. MOGENSEN, 1963. A comparison of various laboratory methods for determining the phosphate condition in soils. Acta Agric. Scand. Stockholm, XII: 315-324.

ANTIPOV-KARATAEV, I.N., 1956. Application of the isotope method to the study of adsorption of eletrolytes by the 
soils in connection with land improvement. IN: IAEA. Proc. UN. first int. conf. peaceful uses atomic energy. Genebra, 12: $130-137$.

ARAMBARRI, P. e 0. TALIBUDEEN, 1959. Factors influencing the isotopically exchange phosphate in soils. Plant and soil. The Hague, XI: $343-376$.

BARROW, G.M., 1961. Physical chemistry. New York, McGrawHi11. $694 \mathrm{p}$.

BEMMELEN, J.M. van, 1888. Die absorptions verbindung und das absorptions vermögen der akererde. Land Wirtch. Ver. Stn. 35: $69-136$.

BINGHAM, F.T., 1962. Chemical soil test available phosphorus. Soil Sci. Baltimore, 94: 87-95.

BITTENCOURT, V.C. e E. ZAMBELLO, Jr., 1973. Comportamento do. fósforo em solos tropicais. I. Isotermas de adsorção. Piracicaba, CENA. 23p. (Boletim Cientifico 012 ).

CATANI, R.A., 1947. Contribuição ao estudo dos fosfatos, sua dosagem, extração e distribuição nos solos do Estado de São Paulo. Piracicaba, ESALQ/USP. 65p. (Tese de Doutoramento).

CHO, C.M., 1961. Note on the use of radioactive isotope to determine the available phosphorus in soils. J. Korean Agr. Chem. Seoul, 1: 1-11.

COOKE, G.W. e J. HISLOP, 1963. Use of anion-exchange resin for the assessment of available soil phosphorus. Soil Sci. Baltimore, 96: 308-312. 
DEAN, L.A. e E.J. RUBINS, 1945. Absorption by plants of phos phorus from a clay-water system; methods and ensuing obser vations. Soil Sci. Baltimore, 59: 437-448.

FARDEAU, J.C. e J. JAPPE, 1976. Nouvelle méthode de détermination du phosphore du sol assimilable par les plantes: ex trapolation des cinētiques de dilution isotopique. Note C.R. Acad. Sci. Paris, SERIE D: 1137-1140.

FIFE, C.V., 1962. An evaluation of ammonium fluoride as a selective extractant for aluminium-bond soil phosphate: II Detailed studies on selected soils. Soil Sci. Baltimore, 93: 113-123.

FRIED, M., 1957. Measurement of plant nutrient supply of soils by radioactive isotopes. IN: Atomic energy and agriculture. Washington, American Association of the Advancement of Science Publ., 49: 1-18.

FRIED, M., 1964. "E", "L" and "A" values. IN: ISSS. 8 th Intern. congr. of soil science. Bucharest, IV3: 29-39.

FRIED, M. e H. BROESHART, 1967. The soil-plant system, in. relation to inorganic nutrition. New York, Academic Press, $358 p$.

GUNARY, D., 1970. A new adsorption isotherm for phosphate in soil. J. Soil Sci. Oxford, 21: 72-77.

GUNNARSON, 0. e L. FREDRIKSSON, 1951. A method for determining the amount of "plant available" phosphorus in soil by means of $32 p$. IN: IAEA. Proc. isotope conf. oxford, I: 423 . 
HEVESY, G., 1923. The adsorption and translocation of lead by plants, contribution to the application of the method of radioactive indicator in the investigation of the change of substance in plants. Biochem. J. Essex, 17: 439-445.

HEVESY, G. e E. HOFER, 1934. Elimination of water from human body. Nature. London, 133: 495-496.

HEVESY, G., 1948. Radioactive indicator. Their application. in biochemistry, animal physiology and pathology. New York, Interscience.

JACKSON, M.L., 1969. Soil chemical analysis advanced course. 2nd ed. Madison, M.L. Jackson. 895p.

KAFKAFI, U. e B. BAR-YOSEF, 1969. The effect of pH on the adsorption and desorption of silica and phosphate on and from kaolinite. IN: Proc. intern. clay conf. Tokio, 1: $691-696$.

KILMER, V.J. e L.T. ALEXANDER, 1949. Methods of making mecha nical analysis of soils. Soil Sci. Baltimore, 68: 15-26.

LAMM, C.G., 1961. A study of isotopic exchanges and chemical conversions between fertilizer-phosphorus and soil phospho rus. Acta Agric. Scand. Stockholm, XI: 95-113.

LANGMUIR, I., 1918. The adsorption of gases on plane surfaces of glass, mica and platinum. J.Amer. Chem. Soc. Easton, 40: $1361-1403$.

LARSEN, S., 1950. Studies on the uptake of phosphorus in plants with radiophosphorus as an indicator. K. veterinaerog landbohojskole. Copenhagen, mimeografado. 
LARSEN, S., 1952. The use of $32 \mathrm{p}$ in studies on the uptake of phosphorus by plants. Plant and Soil. The Hague, IV: 1-10.

LARSEN, S. e I.J. COOKE, 1961. The influence of radioactive phosphate level on the absorption of phosphate by plants and on the determination of labile soil phosphate. Plant and Soil. The Hague, XIV: 43-47.

LARSEN, S. e C.D. SUTTON, 1963. The influence of soil volume on the absorption of soil phosphorus by plants and on the determination of labile soil phosphorus. Plant and Soil. The Hague, XVIII: 77-84.

LARSEN, S., 1974. Phosphorus - a limiting factor in future food production. Neth. J. Agr. Sci. Wageningen, 22: 270274 .

LOTT, W.L.; J.P. NERY; J.R. GALLO; J.C. MEDCALF, 1956. A técnica da anālise foliar aplicada ao cafeeiro. Campinas, Ins tituto Agronōmico. 29p. (Boletim 79).

LOURENÇO, S., 1973. Adsorção e dessorção de fósforo em solos do Estado do Paranā. Piracicaba, ESALQ/USP. 69p. (Tese de Doutoramento).

MATT INGLY, G.E.G. e 0. TALIBUDEEN, 1960. Isotopic exchange of phosphates in soil. IN: Report of the Rothamsted experimental station. Harpenden Herts: 246-265.

MCAULIFFE, C.D.; N.S. HALL; L.A. DEAN; S.B. HENDRICKS, 1948. Exchange reactions between phosphates and soils: Hidroxylic surface of soil minerals. Soil Sci. Amer. Proc. Chicago, 12: $119-123$. 
McCONAGHY, S.; J.W. STEWART; M. MALEK, 1967. Soil-phosphate status as measured by isotopic-exchange and other techniques. IN: JACKS, G.V. Transaction of meeting of comission II and IV of ISSS. (Soil chemistry and fertility). Aberdeen: $151-160$.

MURPHY, J. e J.P. RILEY, 1962. A modified single solutions method for the determination of phosphate in natural waters. Anal. Chem. Washington, 27: 31-36.

NELSON, W.L.; A. MEHLICH; E. WINTERS, 1953. The development, evolution, and use of soils tests for phosphorus availability. IN: PIERRE, W.H. e A.G. NORMAN. Soils and fertilizers phosphorus. New York, Academic Press: 153-188.

NEPTUNE MENARD, L. e A. CAMPANELLI, 1961. Determinação e com paração dos Valores Mi, A, Y e S, em dois tipos de solos do Estado de São Paulo. Anais da ESALQ. Piracicaba, 18: 349-359.

NEPTUNE MENARD, L., 1963. Isotope techniques for the determination of phosphorus in soils. Seminar given at the unit of agriculture - IEAE. Viena, mimeografado. $15 \mathrm{p}$.

NEPTUNE, A.M.L. e T. MURAOKA, 1978. Uso de isōtopos em química e fertilidade do solo - Revisão. R. bras. Ci. Solo. Campinas, 2: 151-163.

NePtUne, A.M.L. e T. MURAOKA, 1980. Comunicação Particular.

NEWBOULD, P., 1963. Relationship between isotopically exchange calcium and absorption by plants. J. Sci. Food and Agr. London, 14: 311-319. 
OLSEN, S.R., 1952. The measurement of phosphorus on the surface of soil particles and its relationship to prant available phosphorus. IN: USAEC/TID. Proc. conf. in the use. of radioisotopes in plants and animal res. Manhattan, 5098: 59-67.

OLSEN, S.R., 1953. Inorganic phosphorus in alkaline and calcareous soils. IN: PIERRE, W.H. e A.G. NORMAN. SOils and, fertilizer phosphorus. New York, Academic Press: 89-122.

OLSEN, S.R. e F.S. WATANABE, 1957. A method to determine a phosphorus adsorption maximum of soils as measured by Langmuir isotherm. Soil Sci. Amer. Proc. Chicago, 21: 144149 .

PAAUW, F. van der, 1971. An effective water extration method for the determination of plant available soil phosphorus. Plant and Soil. The Hague, XXXIV: 467-481.

PIMENTEL GOMES, F., 1975. Curso de estatistica experimental. 7a ed. São Paulo, Livraria Nobel. 430p.

RAIJ, B. van e M.A.T. ZULLO, 1977. Mētodos de análise de so10 para fins de fertilidade. Campinas, Instituto Agronómi co. 16p. (Circular 63).

RENNIE, D.A. e R.B. MCKERCHER, 1959. Absorption of phosphorus by four Saskatchewan soils. Canad. J. Soil Sci. Ottawa, 39: 64-75.

RUSSELL, R.S.; J.B. ERICKSON; S.N. ADAMS, 1954. Isotopic equilibria between phosphates in soil and their significance in the assessment of fertility by tracer methods. J. Soil Sci. 0xford, 5: 85-105. 
RUSSELL, R.S; E.W. RUSSELL; P.G. MARAIS; W.N.M. FOSTER, 1956 . Factors affecting the availability to plants of soil phosphates. IN: IAEA. Proc. UN. first int. conf. peaceful uses atomic energy." Genebra, 12: 103-108.

RUSSELL, R.S.; E.W. RUSSELL; P.G. MARAIS, 1957. Factors affecting the ability of plants to absorb phosphate from soils: I. The relationships between labile phosphate and absorption. J. Soil Sci. 0xford, 8: 248-267.

RUSSELL, R.S.; E.W. RUSSELL; P.G. MARAIS, 195.8. Factors affecting the ability of plants to absorb phosphate from soils: II. A comparison of the ability of different species to absorb labile soil phosphate. J. Soil Sci. Oxford, $\underline{9}$ : $101-108$.

RUSSELL, R.S., 1959. The value of measurements of isotopic dilution in the study of soil-plant relationships. Zeitschrift $f$. Pflanzenernährung Düngung, Bodenkunde. Weinhein, 84: 63-75.

SCHOFIELD, R.K., 1955. Can a precise meaning be give to "available" soil phosphorus? Soil and Fert. Bucks, XVIII: 373375 .

SEATZ, L.F., 1954. Phosphate activity measurements in soils: Soil sci. Baltimore, 77: 43-53.

SERVIÇO NACIONAL DE PESQUISAS AGRONŌMICAS, 1960. Levantamento de reconhecimento dos solos do Estado de São Paulo. Rio de Janeiro, Ministério da Agricultura. 634p. (Boletim 12).

SOKOLOV, A.V., 1956. Determination of availability of soil phosphates and fertilizers with the aid of radioactive iso- 
topes of phosphorus. IN: IAEA. Proc. UN. first int. conf. peaceful uses atomic energy. Genebra, 12: 118-122.

SOKOLOV, A.V., 1959. Supply of available soil phosphates and their accumulation when phosphorus fertilizers are applied. Soviet Soil Sci. Washington, 1: 117-123.

SPOSITO, G., 1980. Derivation of the Freundlich equation for ion exchange reactions in soils. Soil Sci. Soc. Amer. J. Chicago, 44: 652-653.

SUHET, A.R., 1976. Efeito do ${ }^{59} \mathrm{Fe}$ e do ${ }^{65} \mathrm{Zn}$ na produção de matēriá seca e na composição química do feijoeiro (PhaseoZus vuzgaris L.) cv. Carioca e na fixação de nitrogēnio at mosférico em trēs solos. Piracicaba, ESALQ/USP. 73p. (Tese de Mestrado).

SUTTON, C.D. e S. LARSEN, 1963. The residual value of fertilizer phosphate applied in two field experiments. Plant. and Soil. The Hague, XVIII: 267-272.

SUTTON, C.D. e S. LARSEN, 1969. Immobilization of applied phosphate in soil. Welsh soils discussion report. Aberystwyth, 10: 37-41.

TALIBUDEEN, 0., 1954. The determination of isotopically exchangeable phosphorus in some Rothamsted soils. IN: IAEA. Radioisotope conf. proc. sec. conf. 0xford, I: 405411.

TALIBUDEEN, 0., 1957. Isotopically exchangeable phosphorus in soils. II. Factors influencing the estimation of labile phosphorus. J. Soil Sci. 0xford, 8: 86-96. 
TRUOG, E., 1930. The determination of the readily available phosphorus in soils. J. Amer. Soc. Agron. Genova, 23: $874-882$.

UDO, E.J. e F.0. UZU, 1972. Characteristics of phosphorus adsorption by some Nigerian soils. Soil Sci. Soc. Amer. Proc. Chicago, 36: 879-883.

ULRICH, B., 1961. Boden und pflanze, ihre wechselbeziehungen. in physikalisch - chemischer betrachtung. Stuttgart, Ferdinand Enke Verlag. $114 p$.

VANDECAVEYE, S.C., 1948. Biological methods of determining nutrients in soils. IN: KITCHEN, H.B. Diagnostic techniques for soils and crops - their value and use in estimating the fertility status of soils and nutritional requirements of crops. Washington, The American Potash Institute: $199-230$.

VetToRi, L, 1969. Métodos de anālise de solo. Rio de Janeiro, Ministério da Agricultura. 24p. (Boletim 7).

VOLK, V.V. e E.0. MCLEAN, 1963. The fate of applied phosphorus in four ohio soils. Soil Sci. Soc. Amer. Proc. Chicago, 27: 53-58.

WIKLANDER, L., 1950. Kinetics of phosphate exchange in soils. Annals of the royal agr. College of Sweden. Uppsala, 17: 407-424. 